\title{
The Struggle We Share: Writing Anxiety in College Composition and What Teachers Can Do To Help
}

\author{
A Capstone submitted to the faculty of \\ San Francisco State University \\ In partial fulfillment of \\ the requirements for \\ the Degree \\ Master of Arts \\ In \\ English: Composition
}

by

Lauren Kristen Holt

San Francisco, California

Spring 2020

Faculty Advisor: Dr. Tara Lockhart, English Composition 
Copyright by

Lauren Kristen Holt

2020 


\title{
The Struggle We Share: Writing Anxiety in College Composition and What Teachers Can Do To Help
}

\author{
Lauren Kristen Holt \\ San Francisco, California
}

2020

\begin{abstract}
As teachers working within higher education regularly observe, many students either display resistance to academic writing or labor through the composition process with an apparent lack of intrinsic investment. Although reactions such as these cannot be universally explained, one common root cause appears to be writing anxiety. Numerous studies within the higher education fields of Composition, College Counseling, and TESOL have reported upon the prevalence of writing anxiety amongst college students, the possible reasons for this affective response, the manners in which writing anxiety might manifest itself, and the effects it can have upon college learners both in their studies and beyond the realm of academia. However, the literature exploring specific pedagogical approaches writing teachers can take to address and "heal" writing anxiety has been comparably sparse and scattered.

This paper seeks to provide college composition instructors and any other teachers of writing with four flexible approaches they and their students can take to acknowledge and work through the many negative affective responses individuals may have to academic writing. The first two approaches have been developed after an extensive review of the research on emotion in writing, the intersections between identity and academic resistance, and the psychological concept of Flow (Czikszentmihalyi 1975). The latter two approaches have arisen from my experiences as both a student of writing and a writing instructor. In brief, this paper elucidates how the following four pedagogical approaches can help students to navigate and potentially overcome their writing anxieties: 1) Commencing courses with considerable Expressive Writing (EW) and a resulting Literacy Narrative while consciously developing a student-teacher relationship based
\end{abstract}


upon a foundation of empathy; 2) Allowing students more personal choice and freedom in their academic writing so as to alleviate writing anxieties related to identity conflict and reframe composition as a personally meaningful and enjoyable process; 3) Assigning fewer essays of greater depth to promote continual and focused engagement with academic writing while reducing overall workload; and 4) Incorporating mindfulness training techniques into the composition classroom so as to help students negotiate the uncomfortable emotions that may arise during the writing process. 
Dedicated to Dr. James Luotto (1933-2020), Professor of English, DeAnza College 


\section{A Story to Begin}

Some pedagogical practices crush the soul; most of us have suffered their bruising force. Others allow the spirit to come home: to self, to community, and to the revelations of reality."

-Mary Rose O’Reilly, from Radical Presence: Teaching as Contemplative Practice, 3

In my days of writing fiction, I used to sometimes feel that I had to finish the stories I had started, that if I didn't give my characters a voice, nobody would and they would die, very wrongly unheard. With the greatest humility, I confess that I feel much the same way about this essay. There is no one else who could or should write it. Of any piece of academic work I have ever undertaken, this is the one I have most needed to compose.

I would like to start by telling you, as succinctly as possible, the story of how I came to find myself here, writing about writing anxiety. Since the bulk of my readers will likely be practicing or aspiring composition teachers, I imagine that some will find my experiences frustrating, angering, or otherwise unpleasant to digest. For those who understandably react in this way, I urge you to think back to a time, no matter how different in context from mine, when you were in a similar emotional place.

Throughout the bulk of my first year in graduate school, I cohabitated with a tremendous weight in my chest and gut, a feeling not unlike that which follows the loss of a loved one or an unexpected breakup. I found ways to lift this weight now and again, to crawl

free of its oppressive heaviness and bask in moments of hope and relief, but I mostly existed with it pressing on my heart, burning at the back of my throat.

It was not a general distaste for higher education, nor a fear of the work that going back to school would entail, nor a case of clinical depression that mired me beneath this pain. The weight had come from the profound and inexorable feeling that I was in the wrong place, working towards the wrong ends; that composition was not essentially me, that I had steered myself down a path I did not want to be traveling. I have been writing as a hobby since 
childhood and teaching ESL since my early twenties, so earning a degree in composition would seem to most a perfect fit, but I almost immediately felt at odds with the discipline, with the realities of the work to which such an effort would lead, with the whole world of teaching people academic writing. Mere days into my coursework, I found myself drowning in memories of so many micromanaging English teachers; of countless assignments I had completed for someone else instead of myself; of all the stress and unhappiness academic writing had heaped atop the shoulders of my friends in college and my own students when I was a teacher. I was reminded of meetings I had been forced to attend regarding school-mandated rubrics and errors that would guarantee failure; of teachers 'rooms where my colleagues could be found, holding their heads in their hands as they toiled through stacks of uninspired papers; of that sickening realization -many times repressed- that the hours we students spend writing for the academy seem to be largely for the purposes of proving our worth.

What are you doing here? The weight demanded of me. Do you really want to bring this on others?

I believe that the clinical diagnosis for what I was suffering would be an acute identity crisis. Indeed, it felt like a crisis, the worst and most lonesome I have ever personally known. I thereby did everything I could to find a way out of it without giving up on graduate school. When I was not reading, writing, or running my freelance bookkeeping business, I was applying to programs in the field of counseling, whose ultimate aim of helping others find solace and relief seemed the perfect opposite of assigning papers. For reasons not especially pertinent to this story, however, I ultimately decided to remain in the composition program I had begun. I may not have located my place within it, but I could not bring myself to escape, and so I made it my foremost goal to learn from the experience, to come out a stronger person if not an eager applicant to community college positions. Towards this aim, I journaled each night about that weight in my chest. I devoted a great deal more time to my personal meditation practice. I shared my concerns and doubts with a handful of empathetic professors. I took advantage of the 
department's flexibility with electives and enrolled in a full second year of Linguistics and Applied Linguistics courses -(two language-related disciplines I had come to realize were a little more "me"). Most challengingly, I strove to find a personal connection to everything I was asked to do, some lifelong purpose even in those assignments most retraumatizing to me. In practicing these various methods of heightening my awareness, I came to notice the pedagogical approaches that lifted the weight from my heart. In short, I focused on what brought me back to the study of English -noting, too, what pushed me away- and this is what I found:

I am a far more invested and passionate student when I am writing about topics I myself have chosen, when I feel that the efforts of my discoveries will serve me beyond the temporary realm of the classroom. I am a more engaged writer when I feel that my teachers are learning something from what I have put on the page, when I sense that they are picking up my drafts with curiosity, not specific expectations. I am a deeper and clearer-minded thinker when I am not asked to constantly produce, when I am given space to read, think, and ponder. To put this last point more directly, when a course consists of one considerable term paper, supported by a handful of projects directly-related to the development of that paper, I not only produce work of which I am proud; I also feel my resistance towards the discipline slipping away.

Although my experiences are certainly not universal, I intuitively felt that they were not unique either, that the observations I had begun to make of when writing healed me and when it reopened old wounds might serve as the basis for a very informative paper. So began the research that led me to the subject of writing anxiety, the highly prevalent issue I will explore in the pages to follow.

With gratitude for your time and attention, I would now like to shift from the story of my experiences to the story of a struggle we share.

\section{Writing Resistance: Writing Anxiety's Favorite Disguise}

While composing the narrative above, it occurred to me that some of my professors would likely be shocked to read it. Indeed, as teachers, we are not always able to see beneath the 
exterior our students present to us. To my mind, this exterior is where the study of writing anxiety must begin. More specifically, it seems useful to start by investigating one of the most common "disguises" writing anxiety might wear: that of aversion or resistance.

No matter the terminology chosen to describe it, writing resistance -(a.k.a. writing reluctance, passive writing, or writing aversion)- is a familiar challenge to any instructor of academic writing, both within the realm of composition and beyond in other disciplines (Martinez, Kock, and Cass 351). Despite our most ardent efforts at getting to know our students at supporting them in who they are, meeting them where they are, and helping them to put their voices on the page- facing a classroom of learners for whom the task of academic writing appears to be what compositionist Linda Brodkey describes as "a punishing exercise" (qtd. in Sullivan "Aversion" 118) is a disheartening reality of this profession, not to mention a painfully ironic one, considering how liberating and empowering writing $\underline{\text { can }}$ be.

Before moving onward, it is so crucial to point out that this more enjoyable side of writing is not merely known by those of us who have pursued the art as a career. Most children are excited to write when they are young, brimming with curiosity about books and words (Deci 19). As they grow older, however, this intrinsic engagement with literacy tends to fade, a phenomenon which renowned psychologist and motivation researcher Edward L. Deci quite aptly describes as "a profound loss" (19). Addressing this loss within the field of Composition, Patrick Sullivan echoes Deci's concerns, arguing that the prevalence of writing aversion is "a national crisis," not just for higher education but also for society and democracy at large (“Aversion" 119).

The question which unsurprisingly arises from such depressing discussions is how to reverse the trend, how to bring back the natural curiosity and intrinsic investment young children tend to display in literacy practices. Affirming the criticality of this concern are numerous studies on the origins of writing resistance. For me, the most convincing of these took the psychotherapeutic angle, investigating students 'past experiences in writing courses and noting 
the traumas such experiences are apt to inflict on young learners. Poring through these findings is bound to unearth at least one painful memory in most readers. Who amongst us has not had a writing teacher who critically judged their work, who made them feel that they had no place in the business of expressing their thoughts on paper (Williams "Metamorphosis" 149)? A writing teacher who seemed so impossibly "capricious" that they could not be counted on to acknowledge "ability or effort" (McLeod "Some Thoughts" 430)? A writing teacher who foisted upon their students the most repetitive and predictable assignments, within which creativity seemed intentionally stifled (Sullivan "Aversion" 118-120)? A writing teacher who claimed to be supportive of student voice and individuality, but ultimately graded every paper against a set of highly-specific standards? Experiences such as these are too frequently reported to be denied (see Williams; Sullivan; McLeod).

Understandably, the lack of support and freedom so many students report experiencing within academic writing contexts might leave them with a very scarring impression of academic writing: that essays are a form of "transmission," not a process of making knowledge or developing a voice (Paulson and Armstrong 498). In line with this view, these developing writers might come to attribute their struggles with the craft to external factors -faults of the teacher, the school, or the assignment (McLeod Notes 55). As this association with the external strengthens, they might come to see writing as a task to be done for the grade, not for their own learning. Add to all this learned resistance the identity challenges academic discourse almost inherently presents. The world of academia, so different from most of our lives outside of school, does not typically align with the communities we call home or the social classes to which we feel we belong (see Murphy; Williams; Counihan; Hirsh and Kang; Kerr). We may be asked to express ourselves, but the impersonality of the academic institution prevails (Murphy 185), leaving many of us to feel that we must fully adapt and participate, or remain true to ourselves and withdraw. Lastly, I would be remiss not to mention the overwhelming nature of a modern college student's life. Work responsibilities and financial burdens loom large, not only because 
the world is becoming an increasingly expensive place to call home, but also because higher education is excessively costly and -(I would argue)- just a little too job-obsessed. In his memorable piece "On paying Attention: Flagpoles, Mindfulness, and Teaching Writing," composition instructor Barry Kroll quite pointedly critiques the whole enterprise, arguing that universities have become so "market-driven" that the message they predominantly promote is to finish as quickly as possible and learn for the purposes of acquiring a better job (71-72). Bowled over by this marketing and burdened with the rising costs of tuition, students are often in a rush to get out the doors with their degree as quickly as they can. But writing shows little care for those in a rush, and so much of school is writing.

So here we begin with this perfectly understandable picture, one I am sure most composition instructors have both observed and considered: fearful of repeating past mistakes, feeling unworthy of full inclusion or uncertain of how to balance conflicting identities, and likely overwhelmed by a host of financial and social pressures, many students respond to what is arguably the most time-consuming and emotionally-demanding component of higher education with resistance and aversion.

When I started the research for this paper, I did not anticipate writing about writing anxiety. Rather, my early explorations focused solely on issues of investment, like the resistance and aversion I have just addressed. After all, a lack of investment seemed to be at the core of the challenges $I$ had faced throughout my graduate program, as well as at the heart of why so many people I have met and taught have groaned at the mere mention of academic writing. However, while reading the literature on resistance to composition, it became evident to me that many students are so averse to academic writing because of a past -(and potentially ongoing)experience in a literacy context that was emotionally scarring for them (ie. critical judgment of performance and potential; rigidity and exclusive standardization; working hard to fulfill the demands set by an authority figure and still receiving a low grade; being made to feel that they will never be good at the task; feeling that their voice and culture do not belong in the writing 
classroom). Enough of these experiences -(or even just one particularly hurtful episode)- and writing can become an anxiety-inducing task, better resisted than attempted with enthusiasm. If composition instructors do not understand the relationship between the writing resistance we so commonly encounter and the writing anxiety that likely causes it, we run the risk of assuming that writing anxiety is less prevalent than writing resistance and thereby failing to attend to the deeper origin of the latter.

Bronwyn Williams -a compositionist whose insightful and approachable essays often touch on issues of identity and investment within composition- very eloquently describes the relationship between resistance and fear or anxiety: "I tell teachers who ask my advice that quite often what is displayed as resistance in the classroom is likely a manifestation of fear... What might look like boredom, anger, or defiance might actually be defense against getting fooled or hurt again" ("Metamorphosis" 149). Williams is not the only researcher to draw this connection. In relating the prevalence of writing resistance across the disciplines, writing anxiety researchers Martinez, Kock and Cass contend that such resistance "may stem from anxiety" (351), while composition instructor Tracey Baker speculates that students who report being "bored" by writing might be using this word "in place of other words... like 'confused, 'or 'intimidated, 'or 'simply lost'” (407).

Ultimately, teachers of academic writing must remember that although writing resistance might be the most noticeable affective response to composition, it is likely not the heart of the issue. Rather, it appears that writing anxiety, brought on by a number of experiences, is the source of so many student writers 'aversion to composition.

The next few sections of this review will investigate writing anxiety in greater depth, exploring its prevalence, its effect on students, and a number of situations and experiences from which it might originate.

\section{Writing Anxiety: Definitions and Prevalence}


As the most prolifically studied -(though still under-addressed)- affective response to writing, writing anxiety -(or "writing apprehension," as John Daly, the creator of the Daly-Miller Scale of Writing Apprehension termed it more than forty years back)- has been defined in various ways. Susan McLeod's synthesis of these definitions provides us with an accessible starting point. McLeod -a composition professor and prominent researcher of affect in writingrelates that writing anxiety is a state wherein one has "negative, anxious feelings (about oneself as a writer, one's writing situation, or one's writing task) that disrupt some part of the writing process" ("Some Thoughts" 427). More specifically, Daly and Miller argue that those with high levels of writing apprehension generally perceive their performances on past writing experiences to have been unsuccessful and their future success similarly unlikely (qtd. in Crumbo 3). For some, especially adults who have recently returned to higher education, "the demand for writing competency" can be "exceedingly frightening" (Daly and Miller qtd. in Crumbo 1). One particularly striking finding in support of Daly and Miller's claims comes from Zajacova, Lynch, and Espenshade, whose 2005 study of nontraditional CUNY students revealed that term papers were the most stressful academic task of the twenty-seven tasks presented in their survey (qtd. in Navarre Cleary 365).

It is important to clarify, however, that writing anxiety is not a condition predominantly suffered by nontraditional students and Basic Writers, as we may be inclined to assume. Rather, if there is any one facet of academia that binds us all together, it is the challenge of writing. No single writer -be they a community college student, an undergraduate, a Phd candidate, or an emeritus professor- could say that they had not avoided a paper, procrastinated in drafting, worried that their work would not be good enough, fretted that they could never finish what is expected of them, or -perhaps worst of all- felt that they were alone in these struggles. Indeed, numerous studies have shown that skilled and motivated writers often perceive the task of writing as anxiety-inducing (see Britt et. al; Crumbo). Compositionists Ballenger and Myers put it perfectly: "From novices in first-year writing classes to experts at the 
height of their careers," Ballenger and Myers contend, "all writers navigate feelings of anxiety. We do our students a disservice when we ignore the existence and persistence of these feelings" (610).

The word "disservice" is an appropriate one. Though a fear of practicing misinformed psychotheraphy in composition courses has left many writing instructors wary of addressing the affective nature of writing, writing is undeniably more than a cognitive process. It is an emotional one, and, as such, every stage of the writing process is powerfully influenced by affective factors (see Crumbo; McLeod Notes). In short, if we are to teach writing holistically, we must have an understanding of how writing anxiety impacts the learners in our classrooms. This understanding begins with a look at how writing anxiety could be manifesting itself within our students, at what they might be experiencing beneath the resistant, bored, or angry exteriors they present to us.

\section{Effects of Writing Anxiety: From Avoidance to Muscle Spasms}

The effects of writing anxiety are extensive and in many cases debilitating. On the written work itself, high levels of writing anxiety have been shown to result in underdevelopment of ideas, poor organization, greater frequency of errors and papers of insufficient length (Holland; Daly and Miller; Faigley et. al, all qtd. in Britt et. al 695). The impact of writing anxiety on the writer, however, is far more concerning. For many high apprehensives, the cycle commences with avoidance -not only of the writing task itself, but also of classes requiring papers, careers wherein writing is perceived as more likely, and final submission of written work (Daly and Shamo; Crumbo; Reeves, all qtd. in Britt et. al 694-695, 699; see also Woodrow; Holland qtd. in Rose "Writer's Block"). The more students avoid a particular writing assignment, the worse their writing anxiety tends to become. On a physiological level, this anxiety can make its presence known through nervous tension, muscle spasms, and even mouth sores (Navarre Cleary 364; Martinez, Kock and Cass 352). On a psychological level, writing anxiety is known to reduce students 'perceived self-efficacy, or their 
confidence in their writing abilities (Crumbo; Klassen; Rechtien and Dizinno, all qtd. in Martinez, Kock and Cass 357). Such a lack of self-efficacy -(often initiated in early experiences long before college)- can result in an acute fear of failure, yet another factor that can worsen a student's tendency to procrastinate. As procrastination persists, the "tension, anxiety, frustration, and confusion" students experience can "accumulate" and "hinder the writing process," or produce the well-known affliction of Writer's Block (Graves; Rose qtd. in Hunzer 12). Conversely, some highly anxious students, particularly English language learners, may spend an excessive amount of time composing in the hopes of avoiding negative judgments or achieving perfection (Cheng; Howitz, Howitz and Cope; MacIntyre and Gardner, all qtd. in DeDeyn 6; Woodrow 519).

No matter its iteration, it is clear that writing anxiety torments in a cyclical fashion, strengthening its hold over the writer and often becoming a debilitating barrier to a student's academic survival (Starks qtd. in Navarre Cleary 365). Quite tragically, students who have suffered from writing anxiety for much of their academic careers are unlikely to have ever experienced writing as a fully absorbing activity, or a process wherein they might enter a state of Flow (Fleckenstein 125-126). Without any memories of writing as such an engaging and enjoyable experience, these students may not recognize its potential to be so. For me, it is because I know where writing can take me that I am able to persist in spite of the uncomfortable emotions composition inevitably presents. However, to persevere through a process so fraught with challenges without such fond memories is a good deal less likely. As compositionist Kristie S. Fleckenstein puts it, "without these compensating experiences of Flow, the transition from reluctant underprepared writer to involved and proficient writer is more difficult to effect" (126).

So where does writing anxiety originate, and what patterns of similarity exist between the origins of writing anxiety and the origins of the far more easily "diagnosed" condition of 
writing resistance? In this next section, I will briefly outline the most frequent causes of writing anxiety, drawing notable parallels between comparable causes of writing resistance.

\section{Causes of Writing Anxiety: From Past Experiences to Identity Conflict}

Since many of the anxieties we develop throughout our lives originate in previous experience, it follows that writing anxiety, too, would be rooted in our past. In his review of case studies on writing anxiety, N. Barwick found that past experiences are the most common source of writing anxiety (Barwick qtd. in Martinez et. al 352). What seems to make past experiences so influential on a student's later affective response to writing is the damage these experiences can do to a learner's sense of self-efficacy -or their perception of their own writing abilities. Indeed, a lack of self-efficacy cannot simply be blamed on insufficient instruction or practice. Rather, much of the confidence a student brings or does not bring to the writing process originates in whether their confidence as writers was supported in the past, not in how much skill they actually have (Madigan et. al; Pajares, both qtd. in Britt et. al 394). Here we see the first parallel between writing resistance and writing anxiety: that both of these negative affective responses to writing can be caused by unsupportive or judgmental past experiences in writing classrooms.

A starting point for better understanding the relationship between self-efficacy and a student's past experiences is the very theory from which the term self-efficacy comes: Albert Bandura's Social Cognitive theory. Rooted in the belief that knowledge acquisition results from complex interactions between the learner, others and their environment, Bandura's proposal was that a student's sense of self-efficacy could stem not only from self-judgments, but also from past experiences and the "persuasion of others, like a teacher" (Bandura qtd. in Woodrow 520). In her book on affect in writing classrooms, composition researcher Susan McLeod elaborates upon Bandura's theory, noting that many students have learned to feel helpless in the face of writing assignments, sometimes as the result of having received the message that they were not sufficiently gifted in writing to be any good at it (Notes 56; Murphy 185). Likewise, in their 
exceptional summary of the research on the causes of writing anxiety, mindfulness researchers Britt et. al list a number of past educational experiences that are likely to result in the low levels of self-efficacy observed amongst writing apprehensives, such as "explicitly critical evaluation practices" and "negative instructor responses to written work" (Donlon; Donlon and Andreatta; Daisey; Thompson; Daly; Pajares, Usher and Johnston, all qtd. in Britt et al 694; see also Holland 281). In this same paper, Britt et. al point out that restrictions on topic, audience, and time allotted for assignments can also lead to higher levels of writing apprehension (Newkirk qtd. in Britt et. al 694). These common pedagogical practices -(to be explored and critiqued later in Sections II and III)- can leave a developing writer without a sense of control over their writing or the results of the efforts they devote to it (McLeod "Some Thoughts" 429). Understandably, students who have had any or all of these experiences in their early days of literacy instruction are more likely to develop a lower self-perception of their writing abilities and thereby greater anxiety towards academic composition.

Another predominant cause of both writing anxiety and writing resistance is a perceived disconnect between a student's personal identity and the identity they may feel pressured to embody within a college writing classroom (see Hirsh and Kang). Basic Writers and African Americans have been found to struggle with this in particular. As compositionist Ann Murphy explains, Basic Writers may experience an "almost primal guilt...at moving beyond their parents 'education level and thus at leaving their familial language," a guilt which has been shown to correlate with writing anxiety (185). Similarly, as reported by researcher Rochelle Holland, African American students may feel that adhering to the predominant expectation of "standard English" in university writing contexts means abandoning the non-standard dialects with which they most deeply identify (Holland 281). In addition, Holland writes that some African American learners feel a "linguistic insecurity" when faced with college writing assignments, as they have not been supported in learning how to code switch between nonstandard and standard English dialects (280-281). This struggle can result in frustration and 
negative feelings towards writing, as well as the belief that the world of college composition does not seek to include them.

Not unlike the marginalized students just discussed, many adult learners also report feeling detached from the university and thereby anxious about their academic writing. In her study of writing anxiety amongst non-traditional adult students -(or adults who have returned to school at a later age)- Michelle Navarre Cleary explains that these learners -having been outside of higher education for many years or perhaps having never attended college- may feel uncertain as to what the university's standards are and whether they are meeting them (364). Put another way, these students may not yet have a college identity, a fact which can lead to a low sense of self-efficacy and thereby increased writing anxiety. This connection between identity, perceived self-efficacy, and anxiety is also evident amongst the "experienced" or "skilled" writers studied by Ballenger and Myers. As these researchers relate, more advanced writers are particularly prone to anxiety during the revision process, wherein they may feel that their work does not live up to their "writerly identities" and that they are therefore "fraudulent" (592). Ballenger and Myers 'findings remind us of an incredibly important point: that academic writing does not only challenge the identities of learners who have been made to feel excluded by higher education. Rather, even writers who have felt sufficiently at home within the world of academia to continue in their studies -(myself included)- can experience writing anxiety as the result of identity conflicts.

\section{The Proposal}

As we have thus far seen, upsetting past experiences in writing classrooms, as well as conflicts between personal and academic identities can result in low self-efficacy, writing anxiety, and, in many cases, writing resistance. Quite importantly, such negative affective responses to writing do not merely challenge a particular group of students. On the contrary, writing anxiety is widespread, complex, and often not as readily acknowledged as the resistance through which it disguises itself. It is therefore crucial that writing teachers find ways not only 
to avoid causing students further anxiety, but also to help their learners recognize, process, and overcome whatever negative affective responses they may already have to academic writing. Ultimately, such invaluable work can aid our students in experiencing composition as an engaging and personally meaningful process, while the academic writing classroom can hopefully experience its own transformation: from a space unfortunately known for limiting expectations to a community that embraces and thrives on the unexpected.

Before describing a number of approaches teachers can take to helping their students cope with writing anxiety, I feel compelled to defend myself against accusations of naivete by acknowledging the fact that writing is, in its essence, somewhat made for anxiety. The composition process demands of us a tremendous amount of both cognitive and emotional energy, devoted to a host of difficult, frankly draining tasks, many of which have to be redone multiple times throughout the process. Read and reread. Organize and reorganize. Write and rewrite. Consider and reconsider. The whole endeavor, however rewarding, is in many ways masochistic! As researchers B.J. Zimmerman and Albert Bandura more gently put it, writing activities present a unique challenge to an individual's ability to self-regulate in that they "are usually self-scheduled, performed alone, require creative effort sustained over long periods with all too frequent stretches of barren results, and what is eventually produced must be repeatedly revised to fulfill personal standards of quality (qtd. in DeDeyn 53).

Yet there are enough people in this world who enjoy writing, who have developed a fondness for the activity and even devoted their lives to it that we cannot simply dismiss the anxiety composition sometimes causes as an unchangeable feature of the craft. Indeed, though all writers will inevitably experience negative affective responses to the writing process at some point of another, these responses can certainly be caused or exacerbated by a number of factors, many of which college writing teachers can begin to consciously address.

In the remaining sections of this paper, I will propose four pedagogical approaches that can make college composition a less anxiety-inducing experience while helping college writers 
to more healthfully navigate the writing anxieties they bring with them to the classroom. Since past experiences with literacy instruction have been shown to strongly correlate with writing anxiety, the first of my proposed approaches will explore the usefulness of Expressive Writing and Literacy Narratives in helping students work through painful educational memories and reexperience the writing classroom as a place where their stories matter. In this section, I will also reflect upon the importance of cultivating a more empathetic teacher-student relationship and learning community. In response to the identity issues that can lead to writing anxiety, the second healing approach will explore how giving students more freedom in what they write and how they write it can make the composition process more engaging, personally meaningful, and enjoyable. In the third section, I will address what is not addressed enough in composition literature: the benefits to both students and their writing of assigning fewer papers of greater depth. Finally, in acknowledgment of the fact that writing anxiety -(like all emotions)- is experienced somatically as well as psychologically, I will conclude the paper by outlining how contemplative practices, such as meditation and mindful breathing, can help students to productively manage the uncomfortable physiological and emotional responses writing can arouse.

As you read through the sections to follow, you will notice that my suggestions often originate from different theoretical frameworks and pedagogical practices, some drawn from the field of composition, others from applied linguistics and social psychology. Where these theories join, however, is that they are all concerned with improving the well-being of our students. They all contribute valuable insight to the question of how we can make the whole experience of academic writing -from past to present, from external to internal- one that sits well with our learners. Composition needs to be transformed into a process that transforms, an endeavor that does not reopen old wounds, but rather seeks to heal them. I now humbly offer my contributions to the ongoing conversation of how this can be achieved.

\section{Healing Approach I: Expressive Writing, Literacy Narratives,}




\section{and the Cultivation of Empathy}

The feeling of what happens, whether addressed directly or not, profoundly affects what happens."

-Tom Kerr, from A Way to Move, 26

All of us have at some point heard that change begins with awareness, that we cannot overcome our challenges if we do not understand them. As pre-eminent motivation researcher Edward L. Deci writes, people will not change those behaviors that are most self-destructive -(in this context, writing resistance, avoidance, procrastination)- unless they are willing to allow themselves to feel "the feelings that the behaviors are blocking" (163). "The starting place for change," Deci thereby contends, "is accepting oneself and taking interest in one's inner world" (195). Since the overarching aim of this paper is to provide my teacher-readers with methods through which they might help their students transform their relationship with writing, the healing approaches for which I will advocate in this section all center on raising both students' and teachers' awareness of students 'affective responses to writing -what these responses are, where they might come from, and how they have affected the student's experiences in literacy classes. To achieve such awareness, I will propose that composition instructors commence and continue their courses with a considerable focus on low-stakes Expressive Writing (EW). Initially, this EW will be aimed at helping students explore their emotional relationship with writing and construct a Literacy Narrative of uncensored sincerity. Ultimately, however, the daily practice of Expressive or therapeutic Writing will allow students the experience of using writing as a way to consider and process issues of deep personal importance to them. Because such work can be emotionally challenging in and of itself, I will also discuss methods by which teachers can reposition themselves as mentors while reframing the academic writing classroom as an open and empathetic community.

\section{The Undeniable Role of Emotion In Writing}


Before arguing for the ways in which Expressive Writing can help students suffering from writing anxiety, I would like to briefly address those teachers who do not see a place for emotion in academic writing. Despite the pioneering work of Susan McLeod, Alice Brand, and other teacher-researchers who have written at length about the role that affect undeniably and quite importantly plays in all composing processes (see Driscoll and Powell for an exceptional review of the literature), the view that academic writing is and should remain essentially impersonal still dominates throughout the academy, composition studies included. Composition instructor Kia Jane Richmond relates that this resistance to the acknowledgment and incorporation of emotion within the field of composition itself may stem from a distaste for Expressivism, a fear of losing academic legitimacy, or a concern that teachers might inappropriately treat the writing classroom as a therapy session (69-72). Another theory of why composition studies has privileged the rational side of writing centers on the view that many teachers trained within the cognitivist traditions misconcieve of cognition and emotion as unrelated. Yet as McLeod and Richmond remind us, the social and cognitivist theories upon which much of modern composition theory is built are incomplete without the affective element. Indeed, both Vygotsky and Piaget, two social psychologists whose theories of learning have been tremendously impactful to writing studies, very clearly state that all behavior is both affective and cognitive, that the two cannot be separated (McLeod Notes 5-6). Furthermore, any of us who have been moved by the very personal and emotional work of such seminal compositionists as bell hooks, Bronwyn Williams, or Mary Rose O'Reilly -(to name a few of my personal favorites)- know that personal narrative can make academic work more powerful to read, not to mention more engaging and enjoyable to write (Fleckenstein 129). Thus, although we may sometimes feel pressured to teach academic writing as impersonal (Cain 45), to perpetuate the notion that the lived experience has no place in the world of research and analysis, doing so both denies reality and prevents our students from experiencing academic writing as a process of personally meaningful discovery. Moreover, considerable research on the impact of 
emotions on learning has revealed that positive emotions towards all aspects of the educational experience -(ie. subjects, materials, instructors, assignments)- improve academic achievement and facilitate transfer, while negative emotions towards the learning process have the opposite effect (see Driscoll and Powell for an extensive list of relevant studies). So even if one does not personally believe that emotional expression contributes anything of value to academic writing itself, there is no denying that the emotional experience of writing within the academy has an impact on how our students relate to this fundamental component of their education.

In the hopes that I have at least partly convinced my more skeptical readers, I will now synthesize the ways in which Expressive Writing can help our anxious and resistant learners to develop a deeper awareness of their individual affective responses to the composition process, explore questions of profound personal importance to them, and see their voice and life experiences as academically valuable.

\section{Expressive Writing: The Benefits to Students with Writing Anxiety}

No exploration of the psychological benefits of Expressive Writing -(heretofore termed 'EW')- would be complete without an introduction to the work of James W. Pennebaker, the psychologist who has most extensively researched the relationship between EW and recovery from all forms of trauma. Throughout his studies of university students with co-researcher John Frank Evans, Pennebaker found that EW not only offers extraordinary benefits to those suffering from trauma, but also helps beginning college students adjust to their new learning environment, become more open and accepting, and make sense of what they do not understand $(11,13,17$, 49; see also Burkett 190). More recently, research concerned with the impact of positive psychology on the learning process has revealed similar connections between Expressive Writing and student well-being (see Belli for references).

While only some students may bring with them genuine literacy traumas, many may not fully understand their feelings towards writing; still others might not have ever deeply reflected upon these feelings. What Pennebaker and Evans and the research from positive 
psychology collectively convey to us is that all learners can psychologically benefit from a composition course that includes regular low-stakes Expressive Writing, especially that which is aimed at helping students explore their affective relationship with literacy.

Such reflection through EW can also help learners navigate any anxieties that may stem from the feeling that they are writing for their teacher or the academy rather than for themselves. Since personally reflective work foregrounds the students voices, experiences, and interests, it reminds them that their ideas "are worthy of being included" (Nudelman and Schlosser qtd. in Moran 99), that they are the authority over their writing. In this sense, EW can be particularly healing for students whose negative responses to writing originate in the feeling that they do not belong in the world of academia. If encouraged to explore how their emotional relationship with writing might be related to to a possible disconnect between who they are outside of school and who they have felt they should be within it, students can begin to experience writing as a way of integrating personal and academic identities, a process which has been shown to reduce academic anxiety overall (see Hirsh and Kang). Benjamin Batzer addresses this transformative benefit of EW in his beautiful piece "Healing Classrooms: Therapeutic Possibilities in Academic Writing," wherein he describes his experiences of using EW, or "therapeutic writing," with his student-writers on a routine basis. When given the continual opportunity to journal about deeply personal topics, Batzer explains, students "begin to understand the writing process as one of empowerment, where they become the authority figures by writing about events that no one else can." They are also afforded the space to process their past experiences with writing, to "tear out the stitching" and "reconsider the pattern," to use Wendy Bishop's exceptional metaphor (Bishop 132, as qtd. by Batzer), or, as Laura R. Micchiche puts it, to use "wounded attachments" -(in this case attachments to how they feel about academic writing)- "as generative grounds for change... (43)" (Micciche, as qtd by Micciche). 
Beyond offering a method of working through their emotional relationships with writing, EW can help students to become more curious about themselves as learners and more open to their learning process overall. As compositionist Patrick Sullivan -(calling upon the work of Ann Berthoff)- reminds us, such curiosity and openness enables learners to "productively engage the 'chaos 'of real meaning-making" (548) rather than fearing it. Furthermore, curiosity and openness are where intrinsic motivation originates, and intrinsically motivating activities, being by their nature enjoyable, are not experienced as so anxiety-inducing (Sullivan 548).

Expressive or therapeutic Writing also offers long-term, transferable benefits to student writers. Most notably, EW aids in the development of effective monitoring techniques (sometimes referred to as "emotional management" strategies)- that can be transferred to future writing contexts (see Driscoll and Powell and Section IV). As Susan McLeod explains, EW can help students become more aware of emotional cues while writing, like when to start or take a break. Such self-understanding can help students react more effectively to the inevitable unpredictabilities of writing (McLeod Notes 33) and thereby engage with new discourses less anxiously (Chandler 66). Furthermore, if successful writing is largely about "deliberate strategies" for making the task enjoyable (McLeod Notes 32), then low-stakes journaling is an excellent routine to incorporate into our composition courses because it allows students the space to reflect upon which strategies are working for them as writers. In other words, since EW involves less pressure and expectation than a graded assignment, students may be more able to experience the writing process without focusing on the product, to notice what helps and hinders them as writers and carry these lessons with them throughout their academic careers.

\section{How to Incorporate Expressive Writing Into A Course}

Of all the principles guiding our incorporation of Expressive Writing into a composition course, the first should be that we make EW a regular component of our students 'classroom experience from the very start of the semester. To do so not only shows our learners that the 
classroom is a safe space in which they will always have time to reflect, but it also sets a routine wherein their voice, their thoughts, and their concerns are the foundation of the course. Throughout the semester and with the help of one-word prompts and open-ended questions, students should be encouraged to briefly write about whatever is on their minds, to explore the issues that are most consuming, compelling, upsetting, exciting, or quite simply important to them. At the start of the semester, however, I propose that EW prompts should direct students 'attentions to their relationship with academic literacy. By focusing on this theme at the outset of the course, students can begin the incredibly important process of exploring their relationship with writing, a process through which they will find the line of inquiry that will serve as the heart of their Literacy Narrative. In addition, keeping students focused on a general theme throughout their early experiences with EW can introduce them to one of the proven benefits of therapeutic writing: its effectiveness at helping individuals to organize what may begin "as a jumbled and incoherent series of stimulus-induced emotions," and formulate "a coherent story" (Batzer). In future writing contexts, student writers can call upon their experiences of using EW to hone in on a topic for their Literacy Narrative to help them in formulating "coherent" stories out of other jumbled thoughts or emotions.

Although most writers will likely have plenty of struggles to explore when considering their relationship with academic literacy, EW exercises that ask students to consider their emotional relationship with writing should not be solely focused on the negative. In addition to journaling about past experiences in writing classrooms and their emotional struggles with writing, students should be encouraged to reflect upon what helps them write, when writing feels good, or those writing rituals they have discovered that "free up the mind so intuition has space to enter," as McLeod so poetically puts it (Notes 102; see also Miller; Fleckenstein). More specifically, those who struggle with self-confidence as writers may benefit from affirmationbased entries (ie. journaling about a time, academic or otherwise, when they felt successful as a writer; see Pennebaker and Evans 159), while those who experience writer's block or anxiety 
during revision may journal about the "rules" that may be limiting their writing process and how these rules could be productively adjusted (Rose "Rigid Rules" 400). When offering such positive-leaning prompts, however, it is important for teachers to remember that different students will need to write about different things. For some, examining their relationship with literacy through a more positive lens may prove to be both illuminating and healing. For others, their relationship with writing may be so troubled that their energies will be better spent exploring this pain (see Carlo). In the end, students should be encouraged to write about whatever is most helpful, healing, and relevant for them. They should also be encouraged to notice the lines of inquiry or "motifs" -(to use Batzer's terminology)- that repeatedly come up in their journaling, as these can provide fruitful insights into their deepest curiosities, the exploration of which may lead to personally meaningful topics for later research writing.

To help my fellow teachers more clearly envision the incorporation of EW into a college writing course, I would like to share Benjamin Batzer's approach to daily therapeutic writing, as it has resonated with me quite strongly. While I have thus far proposed that students use at least some of their Expressive Writing time -(particularly at the start of the course)- to explore their relationship with academic literacy, I love Batzer's suggestion that we treat the Expressive Writing journal as a space in which students are encouraged to write about the issues "on their minds," whatever those may be. To facilitate these explorations, Batzer offers oneword prompts (ie. "loneliness, betrayal, happiness, justice"), short quotations, and open-ended questions; he also encourages students to follow their own line of inquiry should they have something they really need to think about. In Batzer's class, Expressive Writing occupies the first ten minutes of every session and students always record their thoughts in a single journal. In this way, Batzer explains, they can easily review their entries to see which "motifs" are reoccuring, which questions are of abiding interest. Often, Batzer relates, students use these reoccurring motifs as the starting point for the research writing they will do later in the course, research which is almost always impassioned and engaging. 
Where Batzer's approach differs from the suggestions of Pennebaker and Evans is in his incorporation of regular peer-sharing of EW. Pennebaker and Evans argue that studentwriters -(particularly those who are using their journals to work through a profound trauma)should begin their EW without an authority as audience (16). Not only does this help studentwriters to discover and develop their voice, these researchers contend, but it can also teach them not to worry about how to write something until they have decided what to write (44). Similarly, composition instructor Susan McLeod feels that EW should be ungraded so as to make it less of a performance-oriented exercise (61-62). Batzer, however, has chosen to make EW a less solitary exercise. On a regular basis, he asks his students to sit in groups and share something they have written in their journals; for variety, he sometimes exchanges this oral approach for a written exchange. Most notably, while Pennebaker and Evans join McLeod in arguing that writing cannot be therapeutic if an authority figure is regularly involved, Batzer sees daily therapeutic writing in which the teacher is included as an opportunity to remove the authority figure entirely. To elaborate, Batzer argues that while students are journaling, the teacher should be doing the same. Likewise, while students are sharing the entries of their choice, the teacher should also be sharing. As Batzer explains, "While confessing one's hurt to an audience requires vulnerability, if every member of the class, including the teacher, confronts topics of a personal nature, all share a vulnerability. Shared vulnerability equalizes power dynamics in the classroom by requiring each member to be both writer and reader." This more open approach to EW has proven to be transformative for Batzer as a teacher, for his students as writers, and for his classroom as a community. Empathy and support have flourished, research papers "springing" from these journals and discussions have been "engaging," and his students have come to see writing as personally meaningful, illuminative, healing, and dialogic. Batzer has also come to feel like less of an authority figure, a transformation which has served to heal his relationship with composition. 
In the end, whether trying out Batzer's approach or keeping the Expressive Writing process more private as Pennebaker and Evans and McLeod suggest, composition teachers and their students are likely to experience a number of benefits from incorporating regular therapeutic writing into the course from the very beginning of the semester.

\section{Literacy Narratives: Benefits to Students and Teachers, Approaches and Variations}

In her profoundly moving -(and incidentally very expressive)- work Radical Presence, compositionist and poet Mary Rose O'Reilly writes that everyone has stories "caught in their throat" and that "if we can't pull the weight of these stories off people, it's very hard for them to learn" (28). One such story is our experience with literacy, a story which has been appropriately called the "Literacy Narrative."

One of the field's most vocal advocates of the Literacy Narrative is compositionist Bronwyn Williams. Throughout his years in the classroom, Williams has found that Literacy Narratives are particularly helpful for those who fear or resist writing, as the genre offers a vehicle through which these learners can acknowledge their feelings towards literacy, discover where these feelings might have come from, and reconstruct their academic identity from one given to them by past authority figures to one over which they have control ("Metamorphosis" 150; "Heroes, Rebels" 345; see also George 340). Though other methods of learning about students experiences with writing certainly exist -(ie. Conferences, in-class discussion)- Williams relates that students are "often quite willing to detail how they have been hurt or wronged in literacy classes in ways that they would be much more reluctant to offer in a class discussion or even an individual conversation" ("Metamorphosis" 150). As Williams explains, "finding out about the sources of student fear and resistance" aids him in approaching the material in his courses with more awareness of his audience (150). Such awareness serves as the basis for empathy, the open expression of which has been shown to help students feel less alienated and silenced in school (Corkery 52; Camangian 459). 
Dana Lynn Driscoll and Roger Powell contribute to Williams 'observations in their work on the role of emotion in transfer. The impact of a student's "lived experiences," Driscoll and Powell explain, contributes "to their underlying emotional dispositions and ability to transfer knowledge..." If a student has had mostly negative experiences with academic writing, they are likely to have a negative emotional disposition towards composition. Consequently, this student's ability to both learn in writing classrooms and transfer that learning to future writing contexts will be inhibited. As Driscoll and Powell very accurately contend, "this reaffirms the importance... of better understanding how students 'past personal and educational experiences shape their current identities as writers..." The Literacy Narrative is an excellent vehicle through which we, as teachers, can develop this understanding of where our student-writers are coming from.

The traditional approach to the Literacy Narrative is to have students tell the story of their past experiences with writing in school. The slight variation I am proposing is to have students select one aspect of this experience from their Expressive Writing explorations and develop that aspect into a story for their teacher and peers to read. Not only does this approach allow students the space to explore their relationship with writing from many different angles before settling on the story they want to tell, but it also helps them to find focus within a topic that is likely to bring up an overwhelming tangle of emotions. As compositionist Kristie Fleckenstein reminds us, having a clear goal when we write helps us to experience Flow throughout the composition process (126), an important aspect of engagement and enjoyment (to be discussed in further detail in Section II). By using EW to find the focus of their Literacy Narrative, students will be more able to get into the process of writing it.

One possible point of disagreement regarding Literacy Narratives is whether to have students first read models, such as Anne Lamott's legendary Shitty First Drafts. For some students, learning about the struggles of successful writers could help them to feel less alone (Williams "Metamorphosis" 153) while for others, reading such exceptional models might leave 
them feeling that they are yet again being asked to live up to a standard they do not feel ready to reach, to write like someone else (Corkery 60). Personally, I have always been partial towards offering fewer models, not only to reduce the pressure to imitate but also because I have always been turned off -(as a student)- by the highly prevalent message that writing and reading are overall wonderful, that, in the end, everyone should be glad they have become literate. Though there may be nothing harmful about writing and reading as skillsets, the environments in which we develop literacy can be very harmful. Later in my research on Literacy Narratives, I was thankfully led to the work of Rosanne Carlo, who speaks to these very sentiments. Through the story of her troubled -if ultimately successful- relationship with academia, Carlo argues that students are too often taught to reflect upon their experiences with literacy through "a frame of success." Be it the sample texts they are assigned or the questions they are given as prompts, most students are guided towards the belief that they are expected to write about how literacy has helped them, how it has been a positive experience for them, or how they have grown as writers. But these "success tropes," Carlo contends "force the subject to assume the identity of the ideal academic, a role that may be uncomfortable given someone's life experiences and personality." Furthermore, Carlo continues, framing the Literacy Narrative in such a limited way "flattens" the students 'genuine experiences. It "conceals their emotional labor," and suppresses stories that might address "outlaw" emotions, feelings that run contrary to the "dominant narrative of literacy as success" (Jaggar 166, as qtd. by Carlo). To me, the thrust of Carlo's argument is that we should encourage students to write whatever Literacy Narrative they personally need to. We need to make clear that we are not expecting any particular type of story, but rather looking forward to the story they choose to share with us, however dark and emotional that story may be. By using EW to help students explore their relationship with literacy before they sit down to draft their Literacy Narrative; by offering prompts that do not limit their considerations to experiences of success, and by ensuring that the sample texts we $d o$ ask students to read include some narratives which -like Carlo's- explore traumatic experiences with 
academia, we can show students that we are foregrounding their uncensored voice and experience, not expecting a story they may not be able to tell with sincerity.

Before moving on, it is important to address the fact that the transition from lowstakes, free-flowing EW to a graded Literacy Narrative wherein the teacher has returned as the "evaluator" can be a tricky, potentially retraumatizing one. To help students retain the personal, honest voice they might have started to hear more throughout their low-stakes Expressive Writing, identity researcher Roz Ivanic recommends guided reflection throughout the Literacy Narrative drafting process (Chap. 11). By asking students to consider questions that are aimed at helping them to "make explicit for themselves the the way in which their identity is constructed in their writing" -questions such as Where do you see yourself in this and where not?"; Did you feel under pressure to write any of it in a particular way? Where was this pressure coming from?" (Ivanic Chap. 11)- we can help our learners to more actively attend to the survival of their personal voice in their first evaluated assignment.

\section{The Cultivation of An Empathetic Environment: What Does It Look Like?}

Since empathy is a word used in a vast array of contexts, it seems useful to describe the qualities an empathetic composition classroom would ideally feature. Informed by a wealth of literature on the subject and my own experiences as a teacher and student, I would argue that an empathetic classroom is one wherein students 'personal feelings and experiences are valued, not judged (Teich 147), and teachers show genuine engagement with student ideas (see Geiger 102). In an empathetic classroom, teachers focus on how students have been successful, thereby displaying belief in their abilities (see Crumbo; McLeod Notes on the Heart). Evaluation and competition are de-emphasized while collaborative peer work is encouraged. Throughout this peer work, students are encouraged to share their experiences with writing -(both cognitive and emotional)- rather than just the writing itself (see McLeod Notes). Teachers also share their experiences with writing, both the good and the bad, so as to show their students that they are no less vulnerable to the challenges writing poses than anyone else. Lastly, and perhaps most 
importantly, the empathetic writing instructor displays a desire to listen to the experiences of their students and fully accept whatever they hear. As composition teacher Eric Leake reminds us in his reflections on the subject, "To really understand somebody else, we have to attempt to understand where that person is coming from." Only with a truly open mind can such understanding be achieved.

We will soon look more at how to cultivate more empathy in the college writing classroom. First, however, it is important to investigate how empathy can reduce writing anxiety.

\section{How Empathy Can Alleviate Writing Anxiety}

The ways in which empathy can benefit writing students are so extensive as to warrant a book on the subject. Specific to writing anxiety, however, these benefits can be more concisely presented. On the level of self-perception, fostering empathy in both the composition classroom and the teacher-student relationship has been shown to result in increased self-efficacy (Crumbo qtd. in Martinez et. al 21). Since low self-efficacy is one of the most notable causes of writing anxiety, it follows that this boost in self-confidence effectively decreases writing anxiety (Crumbo qtd. in Martinez et. al 21). Feeling more connected to and supported by one's teacher can also heal negative past judgments that might be contributing to students 'writing anxiety (Crumbo 21, 46). Indeed, in their research on transfer in composition, Driscoll and Powell report that "positive emotional experiences with a faculty member" tend to result in a more "generative experience" for writing students; this experience, in turn, aids student-writers in transferring what they have learned and how they have come to feel about writing to future contexts. Lastly, learning about the challenges experienced by their peers and instructor -(one of the key features of an empathetic classroom)- can help students to feel less alone in their affective struggles with composition (Gere qtd. in McLeod Notes 40).

\section{How to Cultivate Empathy and Become a More Empathetic Mentor}


When I think of empathy -of how it feels to receive it and know I have truly extended itthe first word that comes to mind is listening. There are different ways to listen to people, and empathy entails the most effortful, what Mary Rose O'Reilly and Susan McLeod both refer to as "active listening" (Notes 115-116; O'Reilly 19-21). The sort of active, empathetic listening O'Reilly and McLeod describe does not merely involve nodding, making eye contact, and hearing the words relayed. Active listening necessitates a complete lack of judgment, an openness of heart and mind. As O'Reilly reminds us, much of the listening we do in academia is of a critical nature. Now and then, however, someone truly listens, and it can be a lifechanging experience. As O'Reilly so beautifully relates: "If someone pays attention to the part of me that struggles for transcendence, my search intensifies, the questing spirit grows bold enough to claim its path... One can, I think, listen someone into existence, encourage a stronger self to emerge or a new talent to flourish. Good teachers listen this way, as do terrific grandfathers and similar heroes of the spirit" (19-21).

But how, an overworked teacher might ask, can we truly listen to each and every student? Having been such a teacher myself, I know that this recommendation might sound idealistic. There are, however, ways in which we can listen to our students 'stories beyond holding more conferences than logistically feasible. The Expressive Writing and subsequent Literacy Narrative previously proposed are one; another, complementary approach is to keep the written dialogue between teachers and students open and consistent, even after the Literacy Narrative has been turned in. This can be accomplished in a number of ways. One approach is to follow Batzer's admittedly brave lead and engage in regular sharing of Expressive Writing throughout the semester. If a teacher is not comfortable with this level of vulnerability, empathy researcher Emily Wender offers an alternative form of low-stakes writing that can help to foster an empathetic connection between teachers and their students. In lieu of having students share their regular EW entries, Wender recommends asking students to write impromptu letters to their teacher about how they are feeling about the class, their life in general, and the assignment they 
are working on (36). Such free, but focused low-stakes writing not only keeps the teacher-student dialogue alive, but also helps teachers to know what their students are experiencing as the courses progresses (see also McLeod and Navarre Cleary for more on low-stakes writing and empathy-building). It also allows students to choose what they want to share and when they want to share it. By staying in touch with students in this way, teachers will be better able to take the student perspective, a change in viewpoint which has been shown to result in more curiosity, higher self-esteem, and greater intrinsic motivation and enthusiasm towards learning (Deci 43, 100, 143).

As mentioned previously in my review of Benjamin Batzer's approach to Expressive Writing, regular, open-hearted peer work can be a excellent method of cultivating more empathy in the classroom itself. However we choose to do this, incorporating time into our classes for students to share their experiences with one another can help them to feel less alone in their struggles with composition (Miritello; Morrison, both qtd. in Navarre Cleary 372). We must simply remember that active, empathetic listening requires attention and practice. It can therefore be productive to offer students strategies for listening more actively to their peers, such as orally recalling what they heard after their classmate has finished speaking (O'Reilly 11), or reflecting in a journal on the connections they can find between their classmate's experience and their own.

As students share their experiences with us and with each other, we too need to share our experiences with students, especially the struggles we have had with writing and the strategies we have developed to work through these challenges (see Driscoll and Powell). Ballenger and Myers nicely describe this as modeling "productive vulnerability," explaining that such sharing is productive because it can help to reduce the shame students might feel over their difficulties with writing (612). In telling students of our struggles, we can also start to dispel the prevalent myth that writing comes from "one flood of inspiration," as McLeod puts it, or that it is the result of inherent talent (Notes 41; see also Driscoll and Powell). Rather, 
writing is always a process of navigation, a journey that cannot, by its nature, be devoid of challenges or puzzles to be solved.

Because student writers will almost always feel that a judgment of their writing is a judgment of them and because feedback can significantly impact a student's long-term relationship with writing (see Driscoll and Powell), the openhearted connection we foster in conferences and in class must also be present in our written responses to their drafts. When responding to student writing, we can show our students that we are truly listening by noting where they have taught us something new and making clear our interest in their ideas (see Harrison et. al; Geiger; Thomas 103; Ivanic Chap. 8). We can also focus on where we felt their writing has been most successful and effective (see Holmes; Keithley 95; Navarre Cleary), an approach which Lad Tobin describes as "identifying and realizing potential" (85). In conferences, too, we can ask students how they are perceiving the process, not with the intent of correcting their perceptions, but rather to better understand their experience (Ivanic Chap.

11). Most crucial of all is that we show as much -(if not more)- interest and care in our students themselves as we show in their writing. To quote Sandra P. Burkett, we should always try to respond "first to writers as persons and then to their writing as artifacts" (192; see also Vanderstaay et. al). To make any of these adjustments to our teaching practice can help to reframe the Literacy experience from one concerned with product and standards to one concerned with open communication and the experiences of those communicating.

Another consideration that has really resonated with me is the importance of continually engaging, as writing teachers, in the very self-examination we ask of our students. To truly reposition ourselves as empathetic mentors, we need to do the work we assign. We need to examine our feelings towards Literacy, how we resist writing or grow anxious throughout the process. We also need to take steps, whenever possible, to better understand how our most resistant or anxious students are feeling. One way to achieve this understanding is to take classes ourselves whenever possible, as it can be easy to forget the 
student experience (Thomas 105-6). Another is to follow Wender's advice and write letters, to ourselves or to our colleages, about students we are having an especially hard time understanding or empathizing with. Exploring this disconnect through an Expressive Writing approach such as Wender's letters or regular reflections in a teaching journal might help us to discover what is blocking our ability to understand that student's perspective.

Whatever method we use, we cannot expect the cultivation of empathy to be easy. Like the writing process, putting energy into truly understanding other people can cause both resistance and anxiety. We must remember, however, that we are never alone in any of these feelings. To this point, discussing our challenges with colleagues without merely complaining or passing judgment might help us to work through any disconnects we are experiencing.

\section{Healing Approach II: Freedom, Personal Choice, Identity and Enjoyment}

Education is not the filling of a bucket, but the lighting of a fire."

-W.B. Yeats qtd. in Sullivan “A Lifelong Aversion to Writing...” 120

As we saw in both the introductory literature and my personal confessions, the roots of writing anxiety and the resistance through which it might manifest itself can often be traced to identity conflicts (see Hirsh and Kang; Ivanic; Young; Williams). Though academia has the potential to become a space of solace and comfort, it is not initially an environment in which many students feel at home. Academic communities tend to be very exclusive, a fact which can easily leave any student wondering if they will be able to fit in (Young 6, 8). As Roz Ivanic so aptly puts it in her work exploring writing and identity, learners "often face a crisis of identity, feeling that they have to become a different sort of person in order to participate in these contextspecific and culture-specific knowledge-making practices of academic institutitions" (Chap. 11). When it comes to the task of writing, Ivanic explains, "becoming more literate is in itself an issue of identity... On the one hand, these are likely to be prestigious identities, and so it is in 
people's interests to develop and extend their literacies. On the other hand, they may be alien identities, and this will get in the way of engaging in the literate practices which support them" (Chap. 3). Another powerful voice in the discussion of identity and academic writing is composition instructor Bronywyn Williams. Using classroom observations and student insights as the basis for his reflections, Williams writes that the process of learning academic discourse can leave students feeling alienated from their personal or public selves ("Pay Attention"). Particularly for those who have grown up in cultures where oral communication is more valued than written, Williams relates, the expectations of school may appear to stand in stark contrast to the expectations of the communities more cherished and familiar to them (Williams "Pay Attention"; see also Ivanic; Counihan). Attempting to enter the academic community can therefore leave students full of guilt, as they may blame themselves for distancing themselves from their families or severing ties with their socio-cultural roots (see Carlo; Murphy). These feelings are only exacerbated when students learn to associate academic writing with the suppression of their unique voice and lived experiences. The less a learner is permitted and encouraged to make academic writing autobiographically inclusive and relevant, the more academic literacy is likely to feel like an exercise in submission, either to a single authority figure (the teacher), or to a culturally oppressive institution (the world of academia at large) (Gee 155, as qtd. by Ivanic Chap. 3).

When considering the impact of identity conflicts amongst college writers, it is crucial that we remember the scope of the issue. Feeling out of place in the world of academic writing is not a discomfort experienced merely by Basic Writers or learners from specific cultural backgrounds. Even for those who have felt enough at home within the world of higher education to embark upon the lengthy journey through graduate school, fitting into the tight parameters set by instructors and disciplines can arouse painful questions of belonging. In their study of emotional responses to the revision process, Ballenger and Myers report that highly proficient academic writers who pride themselves on their writing capabilities may feel that their "self- 
concept" has been "violated" when a writing task leaves them feeling vulnerable or less selfefficacious (p. 305). Moreover, as my personal story has hopefully illustrated, writing tasks that are highly controlled can result in disenchantment and unease, even amongst those learners -like myself- who possess the self-efficacy to successfully complete them.

In modern theory, composition is meant to help with the issues I have thus far outlined. Through academic writing, we ask students to share their voices and views, to make their arguments heard, to contribute their unique selves to the disciplines. And yet, all too frequently -(and for reasons that often stem from institutional pressures)- we ask them to do so within strictly assigned topics and inflexible genres. To put it more bluntly, we invite students to be themselves while telling them how to do so. The result is not just papers wherein personal voice is "buried in academic protocol," as Gregory Shafer so pointedly puts it (383), but also students who come to see academic writing as something they are doing for someone other than themselves. This, Roz Ivanic contends, makes writing essentially pointless, as it is impossible for one to engage in any kind of communication without putting oneself into it (Ivanic Chap. 7; see also Williams "Pay Attention"). Exerting excessive control over the writing process also leaves many learners cynical and disenchanted towards the whole endeavor, which they come to perceive as a disingenuous show (Ivanic Chap. 8).

As perpetuating such patterns within composition is both counterproductive and painful, I will now make an argument for allowing student writers more personal choice and freedom in their assignments -choice not just in terms of what they write, but also in terms of how they write it. Because writing about personally meaningful topics allows us to form a connection between who we are outside of school and who we can be within it, having the freedom to do so is essential to overcoming writing anxiety and resistance. Furthermore, since there is no doubt that any inherently challenging process is far more enjoyable when we are intrinsically invested in it, giving our students more freedom does not merely serve to heal anxiety-inducing identity conflicts. Such flexibility also offers learners the chance to finally 
experience a side of academic writing they may have never known: its potential to captivate, illuminate, and engage. Finally, because such freedom can be frightening for students who have grown accustomed to structure, I will conclude this section by briefly exploring ways in which teachers can productively scaffold the personal choice I have proposed.

\section{Freedom, Intrinsic Motivation, and Flow: How Choice Can Heal Writing}

\section{Anxiety and Resistance}

There are many answers to the question of why we should give our students more freedom in their academic writing, the first of which originates with the students themselves. Students want to be in control of their writing. They want to express themselves, to write about topics relevant to their lives, to use their own voice and incorporate their personal experiences. And when they are given the opportunity to do so, they become more impassioned and confident, more like those little kids we have all witnessed, so eagerly telling everyone about their day. Somewhere deep within all of us, I believe, there remains the memory of this sort of exhilarated story-telling, and I think we are all aching to be told we can use $I$ again.

One of the most memorable and touching pieces I read in the research for this paper was Molly Hurley Moran's narrative about how her experience of writing an autobiographical work about a personal trauma helped her to empathize with her Basic Writing students, many of whom regularly expressed a strong aversion to writing. Moran relays that throughout the process of composing this work, she experienced a tremendous amount of doubt, namely that her work would be accepted by the academic community in which she was so deeply involved. In struggling with this doubt over the validity of her personal voice, Moran came to identify with

her Basic Writing students, many of whom had reported loving writing in elementary school and gradually growing to hate it. Moran realized that this change of attitude towards writing was probably due to the fact that they were no longer allowed to write personally, no longer permitted to tell their story freely. 
Moran's narrative not only reminds us that writing anxiety can be experienced by all writers in many different ways -(in her case, it manifested itself as doubt)- but also that encouraging and allowing academic writers to use their own voices and lived experiences in their writing as Moran so longed to do is crucial if we want to foster more confidence and engagement in our learners. The doubt Moran experienced was the result of years of control and restriction, the very control we need to consciously relinquish (see Moran "Towards a Writing and Healing Approach"). By allowing students more choice, and by placing greater emphasis on "expression over conventions," as Nadia Behizadeh puts it, we help them to experience academic writing as a form of storytelling, an experience they may not have had since early childhood (291).

Central to our discussion of writing anxiety thus far has been the fact that aversions to academic writing -like the disinterest observed by Moran- are not one-time feelings; these are not singular distastes for a specific assignment or teacher. Such reactions are representative of an emotional relationship with literacy, a deep-seeded disposition towards the activity as a whole. Yet as we learned in our discussion of EW, we, as teachers, can turn this relationship around through conscious adjustments to our pedagogical practices, one of which is giving our students a considerable amount of freedom in their work. Consider the following comparison: when we guide our students through the writing process with too many rules and models, we not only exacerbate anxieties they may already feel towards writing (Noels et. al 26); we also limit their "originality, risk-taking, and inquiry" (Tobin 17). Likewise, when we assign topics to our students rather than letting them develop their own inquiries, we essentially eliminate curiosity from the writing process. Resistance and boredom naturally result from all these restrictions. Conversely, when students are offered the opportunity to choose what they will write about and how they will go about expressing their ideas, they are more likely to be intrinsically motivated to engage in the process and thereby experience writing as enjoyable. They are also more likely to produce work of which they are proud and feel more confident about their abilities as writers (Driscoll and Powell). Experiencing writing so 
positively can help students to develop a new emotional disposition towards composition overall, a transformed outlook that they can carry with them through future semesters (Driscoll and Powell). Call me optimistic, but I truly believe that a memorably positive writing experience can help students who have long disliked or feared composition begin to recognize why there are people out there who write without anyone asking them to! And why is this exactly, if you'll permit me the digression? Why do we sit down to compose when it is never the easiest process? Because we have "a driving purpose...a burning desire to convey" (Chap. 11), as Ivanic puts it; "an internal need to explore and convey personally important meanings," to quote Knoblauch and Brannon (qtd. in Hunzer 5). Real writing always matters to the writer, and those who have truly experienced composition in this way are not likely to forget it.

At the heart of why we should offer students more personal choice in composition is the aforementioned relationship between freedom and intrinsic motivation, a connection best understood through the findings of two prominent social psychologists: motivation researcher Edward L. Deci and Flow researcher Mihaly Csikszentmihalyi. As previously stated, intrinsic motivation leads to enjoyment, and experiencing a process as enjoyable can be highly transformative. If we want to help our anxious and resistant students to experience writing in this way, we have to first follow motivation researcher Edward Deci's advice and create the "conditions within which others will motivate themselves," conditions wherein students will engage in the task "of their own volition, at their own initiative" $(10,92)$. The way to do so, Deci contends, is through freedom. In his extensive studies on the subject, Deci found that even when people were asked to do something, there was significantly more engagement if they were offered freedom in how to do it. Allowing for meaningful choice "engenders willingness," Deci contends, a willingness which will continue to grow as students realize that they are not merely learning how to write, but rather engaging in a process of personally meaningful exploration (34). This notion of exploration brings us to a key tenet of Mihaly Csikszentmihalyi's legendary book Beyond Boredom and Anxiety. In examining what makes an activity so enjoyable that we 
virtually lose all awareness of the world around us, Csikszentmihalyi writes that "Freedom is the essential criterion," in part because freedom involves the challenge of discovery (25). Over time, Csikszentmihalyi writes, tasks that involve such enjoyable exploration and discovery can become "little worlds of their own," (14) encapsulating experiences to which we willingly return, ever eager for what we will find. When we offer students the freedom to direct their own exploration, we offer them the opportunity to experience writing as a process of discovery, worth doing quite simply for the doing of it.

Yet another reason to give students more freedom in their writing is the self-efficacy and self-sufficiency it engenders. When we allow our students a great degree of personal choice in their writing; when we refrain from telling them what story to tell or how to tell it, they realize that they have things to say, experiences nobody else has had, a perspective nobody else completely shares, a valuable voice nobody else could emulate (see Hunzer). To develop this sense of individuality and worth as an author and member of the academic community can greatly improve a student's self-efficacy because they will no longer see writing as an act of impossible imitation. Moreover, with improvement in self-confidence comes self-sufficiency one marked sign of growth as a writer (see Csikszentmihalyi; Capossela; Hunzer; Harrison et al). As motivation researcher Edward Deci quite fittingly reports, freedom within challenging contexts -(of which writing is certainly one)- "fuels growth... because it allows people to experience themselves as themselves, as the initiators of their own actions." Speaking further to this point, social psychologists Hirsh and Kang relate that integration of identity with academic tasks -(which freedom encourages)- can result in more cognitive and situational flexibility, or a greater ability to successfully navigate new genres in future contexts. Freedom in writing courses therefore helps to develop "competence and autonomy" side by side, the impact of which is lifelong (70-71).

The last argument in favor of giving students more choice speaks to a point too easily forgotten: that our students have a lot to teach us. As identity and composition researcher Roz 
Ivanic puts it, every learner brings a "diversity of knowledges, wisdoms, ways of learning and ways with words" (Chap. 11). By allowing and encouraging our students to write from a place of genuine interest, we open ourselves, our institutions, and our disciplines to perpetual expansion. If such efforts are sustained, it becomes reasonable to hope that the academic culture experienced by future generations of learners might be more open-minded and inclusive, and that some of the issues I am writing about in this paper will no longer be so widespread.

\section{How to Offer Students More Freedom In Their Academic Writing}

One understandable response to the proposal of offering students more freedom in their academic writing is that those learners who need the most help with composition also need the most guidance. Setting these novice writers off without any direction would be far less helpful than giving them clear guidelines within genre-specific learning goals. However, in proposing more freedom, I am not suggesting that we merely tell our students to go off on their own, write about anything they wish, and return with a paper. I am suggesting that we allow, encourage, and help our students to make their own choices in their writing; that we aid them in seeing through personal choice- both the agency they have in their academic work and the value this work can have to them personally. In short, we need to give them the opportunity to "pattern" their "experiences," to quote Csikszentmihalyi, as this is a fundamental component of what makes any creative process enjoyable and engaging (169).

But what about those students who want more structure, many seasoned teachers might understandably ask? What about those who want to be told what to write about and how to do it? Though I have met more students who want structure than those who do not, I still agree with psychologist Edward Deci that such reliance is not in a student's best interests. Throughout his work on intrinsic motivation, Deci argues that those in positions of power, particularly teachers, need to help those they are guiding to break this reliance on structured direction, that such requests result from many years of control and that perpetuating such educational traditions chronically damages intrinsic motivation. Deci relates that many of his students cannot even 
answer when he asks them what they are interested in learning about (148). Because they have come to associate writing with a teacher's interests and directions, they have not learned to conceive of their own curiosities as valid starting points for academic inquiry (see also Hunzer). This, Deci feels, is tragic, and any of us who see learning as a journey of personal interest and discovery would, I am sure, agree. A productive alternative to the excessive guidance students may request is what Deci terms an "autonomy supportive" approach, wherein teachers and other mentors set the "limits as wide as possible" and "allow choice within them" (144-146). In such an approach, we are helping students to get more involved in their writing processes. We are showing them that the work they are doing should stem from their interests, that learning is largely about tapping into personal wonder. In refraining from telling students exactly how to write their papers, we are also helping them to reconceive of writing as a creative and fluid process, not a skill that merely involves learning a set of constricted steps we can always follow (Blake et. al 170-171). Sure, the freedom I have just described may seem far less comforting and far more anxiety-inducing than the structure so many of us feel obliged to provide. That said, I urge my reader to remember what we learned from the research on identity and writing anxiety: that limiting a student's ability to connect who they are to what they are composing only worsens negative affective responses to writing. Furthermore, as preeminent writer's block researcher and renowned compositionist Mike Rose relates, the rigidity with which many writers approach their compositions -(a rigidity arguably learned from years of controlling pedagogical practices)- has been shown to be at the root of writer's block, one of the many causes -(and results)- of writing anxiety. Learning that writing is not about rigidity, but rather about flexibility, Rose found, helps these students move forward with their work ("Rigid Rules" 400; see also Rose “Writer's Block”).

Overall, however, the most powerful counterargument to those who defend pedagogies of control is rooted in love. All of us who have ever fallen in love with writing know that we did not do so while composing something we did not deeply care about. No matter the genre, 
writing is at its best an art of passion, and passion is a personal affair. In All Writing IS Autobiography, Donald Murray addresses this fact. Citing scholar Vera John-Steiner, Murray powerfully argues for giving students the opportunity to obsess over the subjects they are most passionate about, for following O'Reilly's advice that we "honor the hunger with which our students come to school" (1) by supporting their interests, identity, lived experiences, and voice (Murray "All Writing” 73). Helping our students to find their academic obsession, or at least to begin seeing academic writing as an act of intellectual hunger introduces them to what academia is really all about. As Bronwyn Williams puts it, academic writing is the art of "connecting passion, point of view, experience and identity with research, evidence and analysis" ("Pay Attention" 713). What better evidence of this do we have than the fact that most career academics spend their lives obsessing over a handful of questions, deeply important to them as individuals and researchers? Were it not for this level of intrinsic curiosity, the $\mathrm{PhD}$ may no longer exist! And though many of our learners will not ultimately choose a career path wherein academic writing will continue to be necessary, they can only benefit from any pursuit that helps them to find their core curiosities, the questions and issues that drive them to dive into challenging tasks.

All this said, offering our learners some loose scaffolding can help to ease the potentially unfamiliar experience of personal freedom in academic writing. As Kathleen M. Hunzer reminds us, freedoms which are too unstructured can cause anxiety. Thus, informed by the work of D'Aoust, Rose, and Knoblauch and Brannon, Hunzer proposes that teachers offer these freedoms in a scaffolded fashion, providing more guidance in the beginning of the course and gradually diminishing this guidance as the semester progresses (4). This advice aligns with the findings of Flow researcher Mihaly Csikszentmihalyi, who reports that activities people enjoy are those which gradually increase in difficulty (205). To this discussion, Molly Hurley Moran contributes the suggestion that assignments also gradually become more academic, that a course begins with personal writing, like the Expressive Writing and Literacy Narratives I have 
suggested, then continues with assignments which marry personal interests with academic research. The natural question at this juncture is how we can do this, how we can help students to explore personally meaningful questions while still providing them the opportunity to practice academic genres?

Throughout my research for this paper, several projects stood out as excellent aproaches to achieving this goal while still reducing writing anxiety and resistance. One was the bridging project designed by Harrison et. al for a group of college-level ESL students in Finland. In this project, students were asked to write a paper, linking a personal passion with a professional interest and thereby exploring a possibility for their future. Many of these students began their writing course with high levels of anxiety and low levels of investment. Throughout the bridging project, however, they began to feel less like students and more like researchers (17), a turn in attitude which resulted in less anxiety and more investment, perhaps because they were able to internalize the value of personal experience to academic writing (see also Navarre Cleary; Baker) or see how personal experience and research can "interanimate" each other, to use the words of Moran (8). A bridging project can also give students a way to set a clear goal for their personally meaningful writing. Since clear goals have been shown to increase one's chance of experiencing Flow, a bridging project that encourages purposeful choice can help students to experience writing as enjoyable, which will reduce their anxiety towards composition overall (see also Csikszentmihalyi; Miller).

Another relevant benefit of writing projects that bridge personal interests with professional goals lies in the fact that such projects can help students to see the utility of writing to future aspirations, many of which may be more extrinsically motivating to them than writing is in and of itself. In their study of motivation amongst composition students, Williams and Alden report that many students do not see extrinsically motivating reasons to write. Rather, they conceive of academic writing as a task that will never help them beyond the realm of school (102). Our instinct may be to disagree, to tell our students that they are mistaken, that writing is 
in fact beneficial to everyone. To merely object, however, is to react to our students 'feelings and beliefs without empathy. A more conscientious and effective approach is to help our students reconceive of composition as tangibly purposeful to their lives. By offering academic writing projects that help students unite their interests with their possible futures, we can show our learners how writing can be used towards achieving extrinsically motivating goals. In turn, the writing itself will become more intrinsically motivating. Susan McLeod supports this view, pointing out that people place a higher value on tasks which both interest them intrinsically and have "utility" for future goals (Notes 13). Similarly, in her work on investment and identity amongst second language learners, applied linguist Bonny Norton emphasizes that Investment involves agency and identity, hopes and dreams, that it is not just about now, but also about the future (Chap 1). Involving the future in a research writing project can thereby help students to associate the writing process with their overarching desires, an association which will improve intrinsic motivation (Deci 59).

A couple alternatives to the career-focused bridging project proposed by Harrison et. al are ethnographic compositions wherein students research topics important to their communities (see Purnell; Norton Chap. 7) and variations of Ken Macrorie's legendary I-Search Paper. I love Jeffrey Klausman's approach: he asks students to think about a question that currently or eternally matters to them and to write about that, considering what the academic community is saying about the issue and interweaving those voices with their own personal story (193). In the end, Klausman writes, his students become deeply engaged in their work and the papers they produce are far more fascinating to read (193-195).

\section{Healing Approach III: Fewer Assignments of Greater Depth}

When we allow ourselves and our students the time to develop fewer pieces in greater depth, we communicate that writing is valued and that the skills we teach have a value beyond unread classroom exercises."

-Deborah J. Augsburger, “Teacher as Writer: Remembering the Agony, Sharing 
the Ecstasy" 551

Having written personally and professionally for much of my adult life, I know how much time it takes to create meaningful and effective prose. The common requirement of 4-5 papers per term in a single writing class therefore strikes me as incredibly problematic and counter-productive, particularly when those papers are not clearly interrelated in some fashion. Because such an unnecessary workload is also undeniably anxiety-inducing, I will devote the third section of this paper to the argument that fewer assignments of greater depth will reduce students 'writing anxieties, make the writing process more enjoyable, and ultimately result in work of which students will be more proud. This portion of my paper is arguably the most crucial of all, for shockingly little has been written within the field of composition on the subject of student workload. In fact, most of the research I found addressed teacher workload, not that of their learners. If we are to become more empathetic writing mentors, we need to be conscientious of how the demands we make of our students may be too burdensome to result in true meaning-making -the very purpose of writing to begin with.

Before addressing how workload contributes to writing anxiety, I would like to guide my readers through a brief reflection upon the realities of the writing process, in particular upon the time we need when working through a composition. Though the process unfolds differently for every writer, it is always a process and it rarely goes more quickly than we anticipated. Beyond the layers of responsibilities writing generically entails -(brainstorming, drafting, revising, editing)- not to mention the sheer time it can take to express a single idea, the process also necessitates steps between these layers, "little sabbaths" as Mary Rose O’Reilly quite perfectly puts it (46). Sometimes, we need to stop and observe the world around us. Sometimes we need to read more about our topic. Sometimes we need to delay and procrastinate, to go through what Donald Murray calls "rehearsals." In his beautifully composed essay Write Before Writing, Murray explains that we are pushed forward towards the task of actually sitting down to write by the knowledge we accrue of our subject and by our increasing concern for it, a concern which 
cannot develop without sufficient time. All of this is necessary "pre-writing," Murray contends $(376,380)$ however unproductive it may seem when compared to the steps we may have been taught in school, steps which tend to falsely paint writing as a linear process. As compositionist Susan McLeod reminds us, writing is rarely linear. Plans we may have, but they will always be interrupted (432). In addition, McLeod explains, writing requires the careful balancing of "intuition" and "critique" (104), a balance which, in my personal experience, requires mindfullytimed breaks. When we have little time to work through our compositions because we have too many to complete within the brief span of a semester, these "little sabbaths" are no longer feasible and writing can come to feel like a suffocating race. To always experience composition in this way will only perpetuate the anxiety and resistance academic writing too commonly arouses. Indeed, when I reflect upon the writing projects that were most rewarding for me, I find that I was always given considerable time to work through them, to experience every part of the writing process, including the pauses. Unfortunately, after years away from the student experience, it can become all too easy for teachers -(and even easier for the institutions that direct them)- to forget how demanding writing is, to fail to internalize the realities of what they are asking their students to accomplish (for more on this, see Augsburger 549).

In earlier sections of this paper, I advocated for pedagogical approaches that allow and encourage students to incorporate their personal identities into their academic writing. Here, too, I contend that if students are to feel welcome as they are within the world of academic literacy, the reality of their lives outside of school needs to be respected. One way to show such respect is to acknowledge, through the workload we assign, the overwhelming nature of the modern college student's life. As Lindsey et. al remind us in their study of stress amongst learners at HBCU's -(the findings of which corroborate the findings of numerous prior studies at mixed-race institutions)- many students report having too much to do, too many disparate responsibilities, and a tremendous amount of financial burden $(750,753)$. As an understandable result, time management becomes a significant factor of student stress (750). Given that writing requires 
both time itself and the thoughtful management of it, (perhaps the most of any college task), asking our students to complete 4-5 assignments each semester in a single course really means asking them to forgo what may not seem as immediately essential as keeping their job and maintaining their grades -things like sleep, attention to loved ones, and other crucial components of health and happiness. Naturally, one result of continually requiring such sacrifices is that students will come to experience academic writing as anxiety-inducing and incongruous with their well-being. Another is that students may come to view writing as a threat to their lives outside of school and thereby to who they are beyond the realm of academia, another proven cause of both writing anxiety and writing resistance. Quite admirably, many learners still do their best to meet the unrealistic expectations placed upon them. Sadly, this "valiant" effort -as researcher Maria Scordaras describes it in her critique of accelerated writing courses for ESL students- does not always translate to success (277). Indeed, many of the language learners interviewed in Scordaras's study were held back in their writing classes not for lack of effort, but rather because they were given an unfeasible workload (277).

In Beyond Boredom and Anxiety, psychologist Mihaly Csikszentmihalyi relates that being "bombarded" by demands we cannot fulfill leads to anxiety (50). Conversely, Csikszentmihalyi explains, a person can experience Flow, or deep engagement and enjoyment, when the "opportunities for action" are "evenly matched by their capabilities" (50). There is a common narrative in the world of writing -both academic and beyond- that one becomes a good writer by writing, writing, writing! Perhaps because of this narrative, the belief that students need to write more in order to become capable writers pervades. Yet giving students more papers does not necessarily make them more capable writers. Firstly, capability has a lot to do with feasibility, and the feasibility of any task cannot be measured without considering the time and energy available for it. When we regularly assign our students too much writing, the unfeasibility of these demands can lead them to feel less self-efficacious, a false but powerful self-perception which, as we have already seen, lies at the root of both writing anxiety and resistance. 
At this juncture, I would like to clarify that fewer assignments does not mean less writing practice; it means more focused practice of more meaningful depth. The idea is to refrain from assigning numerous unrelated assignments, each of which require students to begin at the surface. Rather, I propose that we ask our learners to work on a handful of related assignments, each of which allows them to delve more deeply into one topic of their choice (see Murray All Writing; Augsburger). Within this model, student writers can build upon their evolving interests (Fleckenstein 131) and have the opportunity to experience their final paper as a mini dissertation of sorts, not in terms of length or rigor of research, but rather in terms of its capacity to render them a fully-engaged explorer. Furthermore, assigning one project of considerable depth and allowing students a generous amount of time to "obsess" over it -(to use the words of Murray All Writing 73)- creates many of the conditions necessary for deep intrinsic enjoyment, or Flow. Indeed, psychologist Mihaly Csikszentmihalyi relates that being able to engage with a thought process without interruption helps us to experience an activity as a "little world of its own" $(14,177)$. Coupled with the personal choice previously described, this approach can show students that writing is their world to create and that the creation of it does not have to come at unreasonable cost.

One reasonable concern about offering fewer assignments is that students will not use the extra time they are being given for the productive "little sabbaths" previously described, but will rather procrastinate unproductively and be no less stressed in the end by their projects. To this, Susan McLeod offers an excellent solution. In Notes on the Heart, McLeod explains that one way to foster an attitude of commitment without assigning constant work is to schedule "time for some incubation" into the course (102). Throughout her years in the classroom, McLeod has been able to do this most productively by offering successive, ungraded drafts of the same paper, an approach which gives her student writer's deadlines without overwhelming them with too many avenues for thought. In short, McLeod's message is that deadlines, combined with a singular focus, will result in deeper and less scattered productivity. To take this recommendation 
one step further, teachers can promote sustained intellectual engagement by encouraging students to consider how their various lines of inquiry, from free-writes to more formal assignments, interconnect. Sandra P. Burkett's approach spoke to me in particular. She asks students to research a topic related to an inquiry or line of thought to which they found themselves returning throughout their Expressive Writing assignments at the start of the semester (194; see also Batzer). In following such advice, we can de-emphasize the completion of assignments, the constant "checking off" of responsibilities, and instead help our learners to understand, through experience, that writing is a process of exploration and discovery, fueled by burning curiosity and facilitated by space for pause.

\section{Healing Approach IV: Using Mindfulness-Based Stress Reduction (MBSR) Techniques to Mitigate Writing Anxiety}

Writing empowers meditation; meditation empowers writing. Insights derived from meditation are the material for writing, and vice versa. And some of the results seem identical - a sense of rejuvenation and control, a centering accompanied by courage, a clearer mind."

-Donald R. Gallehr, from A Way to Move, 22

The final healing approach for which I will advocate is one which addresses the physical component of our emotional responses to writing. As composition instructor and emotion researcher Susan McLeod reminds us, writing is an affective process; as such, it is is bound to have an impact on the body since emotions arouse physiological responses (Some Thoughts 431; Notes 10). Moreover, whatever progress we may make in handling our anxieties, they are generally not easy to permanently overcome. Though writing anxiety may become less debilitating for students as the result of the previous three healing approaches I have described, there will doubtlessly be situations -(occasioned, perhaps, by new genres, instructors, fields, or time away from school)- wherein a writer's anxiety will be revived. Even experienced writers, McLeod explains, will face challenging emotional reactions to the task, as writing is prone to 
unpredictability. These writers, however, will often know how to navigate these reactions and understand them as temporary and natural, whereas less experienced writers tend to react with overarousal or boredom (Notes 31-32). In short, those who are most successful at navigating the affective side of writing develop deliberate strategies for doing so (McLeod Notes 31-32; see also Driscoll and Powell). In this final section, I will explain the particular effectiveness of one such "deliberate" strategy students can use to mitigate the physiological impact of writing anxiety and thereby improve their relationship with writing overall: Mindfulness-Based Stress Reduction techniques, or MBSR. To close, I will also describe a number of MSBR techniques that can be incorporated into the composition classroom, such as meditation, mindful breathing, and "body blogs" (Wenger, as qtd. by Rashedi).

\section{How MBSR Helps to Mitigate Writing Anxiety and Improve the Writing Experience Overall}

Though I imagine that my readers may be familiar with the basic concept of meditation, MBSR is not so widely known. Thus, before reporting on the benefits of MBSR to anxiety and writing, I would like to share Britt et. al's thorough explanation of this contemplative practice:

"University of Massachusetts program founder, Dr. Jon Kabat-Zinn, defines

mindfulness as 'paying attention in a particular way: on purpose, in the present moment, and non-judgmentally '(1994, p. 4)... Mindfulness-based stress reduction clinic attendees learn to recognize thoughts as events, not facts. They develop the ability to modulate their thinking away from anxiety producing self-talk by refocusing their attention to the current moment. This fundamental skill, returning attention to the present moment, gives the mindfulness practitioner an ability to respond to negative or limiting thoughts, sensations, and emotions without rumination (Toneatto and Nguyen, 2007)" (695).

Because many participants of Dr. Kabat-Zinn's revolutionary MBSR program have reported a significant reduction in academic performance anxiety (Hjeltnes et. al 10), researchers 
across the many fields of education have taken an encouraging interest in the application of mindfulness training to various forms of academic anxiety and other negative affective responses to academic learning. The results of these studies have been impressively positive. In 2016, second language acquisition (SLA) researchers Bamber and Shneider reviewed 57 research studies on mindfulness meditation and its effects on anxiety and other forms of stress amongst college-level learners. As reported by Scida and Jones, Bamber and Shneider found that MBSR "was effective in reducing stress in $73 \%$ and anxiety in $100 \%$ of studies reviewed, while mindfulness meditation was effective in reducing stress in $78 \%$ and anxiety in $77 \%$ of studies reviewed" (qtd. in Scida and Jones 578-579). Similarly, mindfulness and education researcher Edward Thompson reports that extensive research upon the effects of mindfulness practices within academic contexts has shown MBSR to significantly improve learners 'ability to manage anxiety, accept themselves as they are, and exercise self-regulation (29), while researchers Conley, Durlak and Dickson relate that mindfulness-based interventions, particularly those delivered in class, have even been found to be more effective than cognitive-behavioral approaches to student anxiety (qtd. in Scida and Jones 579). Mindful breathing, in particular, has been shown to help individuals react to anxiety's onset more healthfully (see Britt et. al and Scida and Jones for extensive lists of studies to this effect). In their study on the effects of mindful breathing on writing anxiety, MBSR researchers Britt et. al found that such training resulted in a "statistically significant decrease in writing anxiety" amongst their study participants (702), as well as fewer mechanical errors in the participants 'writing (693). When directly interviewed about the effects of MBSR training in academic contexts, students themselves have reported that MBSR has resulted in greater concentration, more flexibility in how they approach their learning, and an overall healthier approach to how they relate to their anxiety (Hjeltnes; Binder; Moltu; Dundas, all qtd. in Scida and Jones 579). Furthermore, if coupled with Expressive Writing, contemplative physical practices like MBSR have been shown 
to increase students 'self-confidence, engagement, and positivity towards the learning task (MacIntyre and Gregersen; Shapiro, Brown and Astin, all qtd. in Scida and Jones 580).

It should be noted that the studies thus far presented represent a mere fraction of the energy recently devoted to the value of contemplative pedagogy to higher education in general and composition in particular (see Belli for a thorough review of the literature). Largely thanks to the foundational work of those researchers who have spent the last several decades begging us to pay more attention to the role of emotion in the writing process (ie. Brand, McLeod), many within the field of composition have started to recognize and accept that writing involves far more than cognition. It is truly a process that engages the whole person -mind, body, and spiritand educating the whole person is thankfully becoming a prominent goal of many writing programs today (see Belli; Wenger)

For some, the term "Mindfulness-Based Stress Reduction" entails that techniques bearing this label are primarily about the mind. However, it is important to understand that the cultivation of mindfulness necessitates involvement of the body. Be it inspired by MBSR, yoga, traditional meditation or other physical traditions with spiritual roots- the foremost goal of all contemplative pedagogy is to help students develop more somatic awareness of their learning process, to recognize how their emotional reactions to academic tasks and contexts are impacting them on a physiological level. In slowing down and listening to what their bodies are telling them, students begin to feel the physiological impact of their emotional reactions. Such acknowledgment of the somatic experience of emotions can aid students in becoming more mindful "emotional managers," to use Driscoll and Powell's terminology (see also Wenger, as qtd. by Rashedi), a skill which can lead to greater resiliency, situational flexibility, and positive feelings towards writing (Driscoll and Powell; see also McLeod).

Though the overarching focus of this paper is on the alleviation of writing anxiety, I would like to note -(for the benefit of any skeptics)- that MBSR can benefit all student writers to improve both their experience with the writing process and their writing itself, even those 
students who do not experience considerable anxiety while writing. Composition, after all, is an emotional experience for everyone. For some, these emotions may be more pleasant, but at some point throughout the writing process, every writer will find themselves affectively overstimulated, a little scattered, or brimming with too many thoughts. As Kevin Davis, a long-time meditator and writing teacher contends, this overstimulation is not conducive to good writing. Rather, Davis quite aptly explains that "what we're after" in writing -(and in life in general!)- is "peace of mind" (401). Through Zen practices like meditation, Davis has found that students can approach writing with more of a "beginner's mind" (398). Over time, this ability renders them better able to let go of past strategies, feelings, and notions about writing that may be causing them anxiety or perhaps merely holding them back in their craft (399).

Davis is by no means alone in advocating for the incorporation of mindfulness-based practices into every composition classroom. In his piece exploring the value of meditation to writing, Donald R. Gallehr argues that meditation and writing are mutually empowering, firstly because both practices can produce insights and "a clearer mind" (22), and secondly because successful meditators and successful writers both know they will survive the unpleasant sensations and emotions that may arise during their practices (25). This knowledge allows them to get through these uncomfortable moments and move on, to be aware of their present experience without being controlled by it. As MBSR founder Jon Kabat-Zinn contends, learning how to be at one with the moment in which we are presently living can teach us to control the wanderings of our minds, many of which lead to the emotional responses that hold us back, be those anxious or otherwise (Kabat-Zinn qtd. in Britt et. al 695). Such awareness of the moment, Donald Gallehr has found, can also help us to choose the right moment for writing and revising, to know when we are ready to sit down and work through our thoughts, a skill from which all writers can benefit (29; see also McLeod Notes). Compositionist Barry Kroll perhaps synthesizes these views most effectively. Helping students pay more attention to the world around them and 
the world within, Kroll contends, is the ultimate responsibility of the writing teacher (73-76). To this end, Kroll often commences his classes with 5-10 minutes of meditation (76).

Another argument in defense of using mindfulness techniques in the composition classroom relates to how these practices can aid us in writing more simply and sincerely. In his resonant essay Silence, composition legend Peter Elbow explains the importance of silence to the writing process. Writing, Elbow contends, is a lot more about "what is left out" than what is put in (12). When we sit down to write, there may be a multitude of voices or thoughts "jabbering" at us (15). Through the conscious practice of silence, however, we can begin to realize which voices not to listen to and get more in touch with our "inner speech," or the stream of consciousness we may not typically be aware of (see Moffett). Accessing this inner speech, I would argue, allows us to hear our most authentic voice, speaking clearly through all the jabber, and when we are able to write with this voice in our ear, our compositions become more sincere. For simplicity, too, we need to slow down the process; we need to "stay" with a thought, as Micciche puts it (Staying). I like to sit with my thoughts for awhile. I like to let them bounce around like little kids at a party until the bulk are too burnt out to pester me further. Then I can see what remains in the end, which ideas have the strength to endure.

Throughout my research of contemplative practices in academia, I also noted a connection between the outcomes of MBSR and the previously-described experience of Flow. In Beyond Boredom and Anxiety, Mihaly Csikszentmihalyi explains that when people are in a state of Flow, "the doing is the thing" (37); consequently, anxious, doubtful questions tend not to enter the mind (38). This is because the individual is fully engaged in the activity, virtually incapable of being distracted. Since mindfulness practices have been shown to both improve focus and concentration and draw learners 'attentions away from the product and into the learning process (see Hjeltnes et. al), such techniques could help students to more easily enter a state of Flow when writing. In other words, MBSR could help students to experience writing as intrinsically engaging and rewarding, two characteristics of activities we willingly return to. 
Equally relevant to a discussion of MBSR, writing, and Flow is Csikszentmihalyi's finding that "kinesthetic microflows," or everyday activities which are physically engaging and enjoyable, are linked to positive self-perception and intellectual flexibility (159). Considering the fact that meditation and mindful breathing are physical experiences which bring attention to our bodies -(the very definition of "kinesthetic")- helping students to incorporate MBSR practices into their writing process could potentially improve their self-efficacy as writers -("selfperception")- as well as their ability to attend to the inherent unpredictability of writing ("intellectual flexibility"). In support of this argument are the findings of Aslak Hjeltnes and his fellow MBSR researchers, who relate that students who learned mindfulness techniques in their writing classes reported more self-acceptance during times of struggle -(an aspect of selfefficacy)- and a greater sense of agency upon realizing that they could control how they reacted to the process (10).

A final benefit of MBSR that should be noted is its positive effect on the classroom community. In Section I, I addressed the importance of cultivating an empathetic environment in our writing classes and reframing ourselves as supportive mentors. In their study of the effects of MBSR on foreign language learners experiencing writing anxiety, Scida and Jones found that students who engaged in such contemplative practices "perceived their teachers to be caring and supportive, and many experienced the class community to be close-knit" (593). Limited though my sources may be for this specific advantage of MBSR training, it should not be discounted, as any approach which improves our learners 'perceptions of their literacy classrooms; any approach which makes the writing classroom feel to our students like a community to which they belong is worthy of experiment.

\section{How to Incorporate MBSR Techniques Into the Composition Classroom}

Barry Kroll commences his composition classes with 5-10 minutes of meditation, sometimes followed by 30-40 minutes of silent writing (76). Peter Elbow humorously remarks 
that asking for 5-10 minutes of silence in class now and then couldn't make his students think him any crazier than they already do! (19). Yet beyond the popular prescription of 5-10 minutes of silent time, how can a composition teacher specifically incorporate evidence-based approaches to mindfulness into their course? A wealth of suggestions have been made in the literature on incorporating meditation, MBSR, and other contemplative practices into academic settings. Here, I will highlight those I have found personally helpful.

As an avid yogi myself, I cannot say enough about the benefits of mindful breathing. This simple strategy of stress reduction can be utterly life-changing, so much so that those who get into breath work tend to become lifelong devotees. For students in particular, the straightforward practice of regulating one's breathing -(known in yoga as pranayama)- has been shown to assist in the development of emotional awareness and emotional management strategies (Wenger, as qtd. in Rashedi), especially when novices are gently reminded to let negative thoughts pass, unjudged and unegaged with. Quite practically, too, mindful breathing techniques are incredibly easy to teach and learn and can prove effective in short spans of time. Along similar lines, body scanning and body awareness exercises have also appealed to many of the participants in MBSR studies within university settings (see Scida and Jones; Davis, Eshelman and McKay all qtd. in Martinez, Kock and Cass 358). In addition to being easy to learn and not at all time-consuming, students can use these kinesthetic MBSR techniques wherever and whenever they might need them, often without drawing the attention of others. Mindful breathing meditations and body scanning exercises are therefore highly transferable, versatile, and appealingly private "tools" for managing emotions within and beyond the classroom.

Visualization or guided imagery techniques have also proven helpful for students who struggle with writing (Davis et. al qtd. in Martinez et. al 358; see also Scida and Jones for a wealth of resources). Through mindful visualization, students can set goals or intentions (Scida and Jones 583), envision successful writing experiences (Ayres and Hopf 193), and get in touch with "their writerly intuition," to use the words of Susan McLeod (Notes 101). For those who 
need to be doing something while they meditate, freewriting and journaling are an excellent complement to MBSR (see Scida and Jones for support; see also Elbow) while moving meditations have proven popular with Christy Wenger's students. Wenger, a contemplative pedagogy advocate and certified yoga instructor, has found that incorporating basic yoga into her writing classes has helped her student-writers to "approach the learning and writing process more responsibly," strengthening their "openness, persistence, and metacognition" (Wenger as qtd. by Rashedi). Wenger also encourages students to practice movement when writing at home and to reflect upon the relationship between their body and their writing process in a "body blog," an ongoing journal in which students might respond to questions relating to the sensory experiences they have while writing, or how they physically feel when their writing is progressing in a particular way (Wenger as qtd. by Rashedi). This sort of work is necessary, Wenger argues, if we want to "undo the educational system's long-lasting dualism of the mind and body" (Wenger as qtd. by Rashedi), a point with which I could not agree more. Personally, I have found nothing more helpful when revising than taking breaks to stretch, move, and breathe.

When considering how to incorporate contemplative practices into their composition classrooms, teachers simply need to remember that there is no one-size-fits-all approach to mindfulness, that students will ultimately need to choose how to spend their periods of silence. The job of the teacher as I see it is merely to share what MBSR approaches they have found personally beneficial and to elicit further suggestions from their learners, many of whom might already have a mindfulness practice they would happily describe for their peers. Whatever techniques are taught and practiced, teachers who introduce MBSR into their composition classrooms need not worry that such activities are less effective in a group setting. To the contrary, researchers Hjeltnes et. al report that supportive group environments can greatly enhance the benefits of mindfulness training because students find great comfort in the realization that they are not alone in their anxieties (9; see also Scida and Jones), a fact which should come as no surprise for those of us who have experience in group meditation, Yoga, or 
other spiritual-physical practices. Lastly, strange though it may seem to some of our students -to sit in silence and focus on their breathing alongside their peers- there is far more benefit than harm in learning such simple tools for self-healing. There is also the undeniable fact that there is a lot more to writing than what we traditionally share with our students. After years of meeting writers, I have yet to find one who doesn't do some special thing when they're stuck in their work, some practice or ritual -(contemplative or otherwise)- that helps them get in touch with their story. If it is the job of the mentor to share, why shouldn $t$ we share all the tools we have found? To me, there is nothing so strange as to keep teaching writing as writing alone. Writing is the mind and the heart and the soul, the body and the emotions that fill it. No matter the genre, that is the truth, and if we want to read papers that make us sit back, that put smiles on our faces and tears in our eyes and ideas in our heads we have not thought before, then it's time we accept what it takes one to get there and share every secret we can.

\section{Some Thoughts to Conclude}

With the utmost sincerity and not a shred of exaggeration, I confess that finding my place within a field in which I had felt so incredibly lost almost instantly lifted that weight from my chest. Even loved ones observed I was lighter. With the help of my trusty meditation practice and my little red journal; with the empathetic support of a few very understanding teachers and the freedom I was given to select the direction of my research, I was finally able to find my way to a topic I just $\underline{\mathrm{had}}$ to explore. And because I was given an ample amount of time to explore this topic -to read, and reflect, and reconsider, and write, and pause when the writing demanded it- I am now sitting here, proud of the thoughts I have shared and how sincerely I have shared them. The most beautiful creations, academic or otherwise, do not come from a compromised heart.

In this paper, I have advocated for a number of pedagogical approaches to reducing the amount of anxiety and resistance so many of our college writers experience towards composition. These suggestions are meant to offer my readers with adaptable choices, each 
sufficiently supported by the research of compositionists, applied linguists, social psychologists, and -most importantly- practicing teachers. Some of you may choose to experiment with Expressive Writing and Literacy Narratives in an effort at healing past wounds. Some may prefer to focus on the cultivation of empathy. Some may make pedagogical adjustments to assignment design in order to prioritize freedom of choice and depth of exploration. Some may give mindfulness training or other contemplative practices a try. Ultimately, whichever of my suggestions you have found sufficiently convincing to attempt in your classroom, I hope your experiments result in less resistance and anxiety, more self-confidence and belonging, and a tangible energy of passion, investment, and openness. It is time that those of us in the field of teaching writing fully embrace the affective nature of the enterprise and do everything we can to help our learners realize what a personally rewarding and truly transformative experience academic writing can be. I stand as proof that it is never too late. 


\section{Works Cited}

Augsburger, Deborah J. "Teacher as writer: Remembering the agony, sharing the ecstasy." Journal of Adolescent \& Adult Literacy 41.7 (1998): 548-552.

Ayres, Joe, and Tim Hopf. "Coping with writing apprehension." (1991): 186-196.

Baker, Tracey. "Boredom in the first-year composition classroom." Teaching English in the Two Year College 30.4 (2003): 404.

Ballenger, Bruce, and Kelly Myers. "The Emotional Work of Revision." College Composition and Communication 70.4 (2019): 590-614.

Bamber, Mandy D., and Joanne Kraenzle Schneider. "Mindfulness-based meditation to decrease stress and anxiety in college students: A narrative synthesis of the research." Educational Research Review 18 (2016): 1-32.

Behizadeh, Nadia. "Xavier's take on authentic writing: Structuring choices for expression and impact." Journal of Adolescent \& Adult Literacy 58.4 (2014): 289-298.

Blake, Michelle F., Charles A. MacArthur, Shannon Mrkich, Zoi A. Philippakos, and Ilknur Sancak-Marusa. "Self-regulated strategy instruction in developmental writing courses: How to help basic writers become independent writers." Teaching English in the Two Year College 44.2 (2016): 158. 
Brand, Alice G. "The why of cognition: Emotion and the writing process." College Composition and Communication 38.4 (1987): 436-443.

Brand, Alice. "Social cognition, emotions, and the psychology of writing." Journal of advanced composition (1991): 395-407.

Britt, Megan, Shana Pribesh, KaaVonia Hinton-Johnson, and Abha Gupta. "Effect of a mindful breathing intervention on community college students 'writing apprehension and writing performance." Community College Journal of Research and Practice 42.10 (2018): 693-707.

Burkett, Sandra P. “The Butterfly Effect: Writing from Chaos to Composure.” Presence of Mind: Writing and the Domain Beyond the Cognitive, Edited by Alice G. Brand and Richard L. Graves, Boynton/Cook Publishers, 1994.

Cain, Mary Ann. "Moved by 'Their 'Words: Emotion and the Participant Observer." A Way to Move: Rhetorics of Emotion \& Composition Studies, edited by Dale Jacobs and Laura R. Micchiche, Boynton/Cook Publishers, 2003.

Camangian, Patrick. "Making people our policy: Grounding literacy in lives." Journal of Adolescent \& Adult Literacy 54.6 (2011): 458-460.

Capossela, Toni-Lee. "Students as sociolinguists: Getting real research from freshman writers." College Composition and Communication 42.1 (1991): 75-79.

Carlo, Rosanne. "Countering Institutional Success Stories: Outlaw Emotions in the Literacy Narrative." Composition Forum. Vol. 34. Association of Teachers of Advanced Composition, 2016.

Chandler, Sally. "Fear, teaching composition, and students' discursive choices: re-thinking connections between emotions and college student writing." Composition Studies 35.2 
(2007): 53-70.

Corkery, Caleb. "Literacy narratives and confidence building in the writing classroom." Journal of Basic Writing (2005): 48-67.

Corrigan, John R. "Teaching writing to dyslexic students: A guide for the composition instructor." Teaching English in the Two Year College 24.3 (1997): 205.

Counihan, Beth. "Freshgirls: Overwhelmed by discordant pedagogies and the anxiety of leaving home." Journal of Basic Writing (1999): 91-105.

Crumbo, Ginger B. Writing Apprehension and the Effects of I Think I Can, I Think I Can". Diss. Spalding University, 1999.

Czikszentmihalyi, Mihaly. Beyond Boredom and Anxiety: The Experience of Play in Work and Games. Jossey-Bass Publishers, 1975.

Davis, Kevin. "This Is the Story of How We Begin to Forget: Zen and the Art of Not Teaching Writing." Teaching English in the Two Year College 38.4 (2011): 398.

Deci, Edward L. and Richard Flaste. Why We Do What We Do: Understanding Self-Motivation. New York, Penguin, 1995.

DeDeyn, R. "Student identity, writing anxiety, and writing performance: A correlational study (Master's thesis)." Retrieved from ProQuest Dissertations and Theses database.(UMI No. 1493752) (2011).

Driscoll, Dana Lynn, and Roger Powell. "States, Traits, and Dispositions: The Impact of Emotion on Writing Development and Writing Transfer across College Courses and Beyond." Composition Forum. Vol. 34. Association of Teachers of Advanced Composition, 2016. 
Elbow, Peter. "Silence: A Collage." Presence of Mind: Writing and the Domain Beyond the Cognitive, Edited by Alice G. Brand and Richard L. Graves, Boynton/Cook Publishers, 1994.

Fleckenstein, Kristie S. "Mental Imagery, Text Engagement, and Underprepared Writers." Presence of Mind: Writing and the Domain Beyond the Cognitive, Edited by Alice G. Brand and Richard L. Graves, Boynton/Cook Publishers, 1994.

Gallehr, Donald R. "Wait, and the Writing Will Come: Meditation and the Composing Process."

Presence of Mind: Writing and the Domain Beyond the Cognitive, Edited by Alice G. Brand and Richard L. Graves, Boynton/Cook Publishers, 1994.

Geiger, T. J. "An Intimate Discipline? Writing Studies, Undergraduate Majors, and Relational Labor." Composition Studies (2015): 92-112.

George, Sheldon. "The performed self in college writing: From personal narratives to analytic and research essays." Pedagogy 12.2 (2012): 319-341.

Harrison, Marlen, Maiju Uusipaikka, Annika Karinen, Tanja Räsänen, Diana Raitala, Reetta Ellonen, Hanna Huumonen, and Otto Tuomela. "Bridging passion and profession: Supporting agency and investment in multilingual university writers." Language Learning in Higher Education 3.1 (2013): 1-25.

Hirsh, Jacob B., and Sonia K. Kang. "Mechanisms of identity conflict: Uncertainty, anxiety, and the behavioral inhibition system." Personality and Social Psychology Review 20.3 (2016): 223-244.

Hjeltnes, Aslak, Per-Einar Binder, Christian Moltu, and Ingrid Dundas. "Facing the fear of failure: An explorative qualitative study of client experiences in a mindfulness-based stress reduction program for university students with academic evaluation anxiety." 
International journal of qualitative studies on health and well-being 10.1 (2015): 27990.

Holmes, Lynda A. "What do students mean when they say," I hate writing"?" Teaching English in the Two Year College 29.2 (2001): 172.

Holland, Rochelle. "Writing experiences of community college students with self-reported writing anxieties and linguistic insecurity: a perspective for college counselors." Community College Journal of Research and Practice 37.4 (2013): 278-295.

Hunzer, Kathleen M. Alleviating composition anxiety, writing apprehension, and writer's block through structured freedom. Diss. West Chester University, 1994.

Ivanič, Roz. Writing and identity: The discoursal construction of identity in academic writing. John Benjamins, 1998.

Keithley, Zoe. " 'My Own Voice: Students Say It Unlocks the Writing Process." Journal of Basic Writing (1992): 82-102.

Kerr, Tom. "The Feeling of What Happens in Departments of English." A Way to Move: Rhetorics of Emotion \& Composition Studies, edited by Dale Jacobs and Laura R. Micchiche, Boynton/Cook Publishers, 2003.

Klausman, Jeffrey. "Resurrecting the 1-Search: Engaging Students in Meaningful Scholarship." (2007).

Kroll, Keith. "On paying attention: Flagpoles, mindfulness, and teaching writing." Teaching English in the Two Year College 36.1 (2008): 69.

Leake, Eric. "Writing Pedagogies of Empathy: As Rhetoric and Disposition." Composition Forum. Vol. 34. Association of Teachers of Advanced Composition, 2016. 
Lindsey, Robert, Saeedah Reed, Robert Lyons, Denisha Hendricks, Antonia Mead, and Karen L. Butler. "Sources of stress among gender and classification for African American college students." College Student Journal 45.4 (2011): 749-758.

Martinez, Christy Teranishi, Ned Kock, and Jeffrey Cass. "Pain and pleasure in short essay writing: Factors predicting university students' writing anxiety and writing selfefficacy." Journal of Adolescent \& Adult Literacy 54.5 (2011): 351-360.

McLeod, Susan. "Some thoughts about feelings: The affective domain and the writing process." College composition and communication 38.4 (1987): 426-435.

McLeod, Susan. Notes on the Heart: Affective Issues in the Writing Classroom. Southern Illinois University Press, 1997.

Micciche, Laura. "Staying with emotion." Composition Forum. Vol. 34. 2016.

Miller, Hildy. "Sites of Inspiration: Where Writing Is Embodied in Image and Emotion." Presence of Mind: Writing and the Domain Beyond the Cognitive, Edited by Alice G. Brand and Richard L. Graves, Boynton/Cook Publishers, 1994.

Moffett, James. "Writing, Inner Speech, and Meditation.” College English, Vol. 44, No. 3 (Mar., 1982), pp. 231-246.

Moran, Molly Hurley. "Toward a writing and healing approach in the basic writing classroom: One professor's personal odyssey." Journal of Basic Writing (2004): 93-115.

Murray, Donald M. "Write before writing." College Composition and Communication 29.4 (1978): 375-381.

Murray, Donald M. "All writing is autobiography." College Composition and Communication 
42.1 (1991): 66-74.

Murphy, Ann. "Transference and resistance in the basic writing classroom: Problematics and praxis." College composition and communication 40.2 (1989): 175-187.

Navarre Cleary, Michelle. "Anxiety and the newly returned adult student." Teaching English in the Two-Year College (TETYC) (2012): 364.

Noels, Kimberly A., Richard Clément, and Luc G. Pelletier. "Perceptions of teachers' communicative style and students 'intrinsic and extrinsic motivation." The Modern Language Journal 83.1 (1999): 23-34.

Norton, Bonny. Identity and language learning: Extending the conversation. Multilingual matters, 2013.

O’Reilly, Mary Rose. Radical Presence: Teaching as Contemplative Practice. Boynton/Cook Publishers, 1998.

Paulson, Eric J., and Sonya L. Armstrong. "Mountains and pit bulls: Students' metaphors for college transitional reading and writing." Journal of Adolescent \& Adult Literacy 54.7 (2011): 494-503.

Pennebaker, James W., and Janel D. Seagal. "Forming a story: The health benefits of narrative." Journal of clinical psychology 55.10 (1999): 1243-1254.

Pennebaker, James W. and John F. Evans. Expressive Writing: Words that Heal. Idyll Arbor, Inc., 2014.

Purnell, Rosentene B. "Islands and Exiles: The College, the Students and the Community in Writing Programs." College Composition and Communication 24.2 (1973): 144-149.

Rashedi, Roxanne. "Review of Christy Wenger's Yoga Minds, Writing Bodies: Contemplative 
Writing Pedagogy."

Richmond, Kia Jane. "Repositioning emotions in composition studies." Composition Studies 30.1 (2002): 67-82.

Rose, Mike. "Rigid rules, inflexible plans, and the stifling of language: A cognitivist analysis of writer's block." College Composition and Communication 31.4 (1980): 389-401.

Rose, Mike. Writer's block: The cognitive dimension. SIU Press, 2009.

Scida, Emily E., and Jill E. Jones. "The impact of contemplative practices on foreign language anxiety and learning." Studies in Second Language Learning and Teaching 7.4 (2017): 573-599.

Scordaras, Maria. "Just not enough time: Accelerated composition courses and struggling ESL writers." Teaching English in the Two Year College 36.3 (2009): 270.

Shafer, Gregory. "Higher level thinking, writing, and democracy among community college students." Community College Journal of Research and Practice 37.5 (2013): 382-387.

Sullivan, Patrick. "' A Lifelong Aversion to Writing": What If Writing Courses Emphasized Motivation?." Teaching English in the Two Year College 39.2 (2011): 118.

Sullivan, Patrick. "Essential habits of mind for college readiness." College English 74.6 (2012): 547-553.

Sullivan, Patrick. "The UnEssay: Making room for creativity in the composition classroom." College Composition and Communication (2015): 6-34.

Sullivan, Patricia A. "Composing culture: A place for the personal." College English 66.1 (2003): 41-54. 
Teich, Nathaniel. "Teaching Empathy Through Cooperative Learning.” Presence of Mind: Writing and the Domain Beyond the Cognitive, Edited by Alice G. Brand and Richard L. Graves, Boynton/Cook Publishers, 1994.

Thomas, Trudelle H. "Generous Listening: A Deeper Way of Knowing." Presence of Mind: Writing and the Domain Beyond the Cognitive, Edited by Alice G. Brand and Richard L. Graves, Boynton/Cook Publishers, 1994.

Thompson, Edward. "Mindfulness for students and the adults who lead them. School administrators have complex jobs. Mindfulness offers strategies and practices to help leaders manage and care for themselves, so they can manage and care for others." Leadership 47.3 (2018): 28-32.

Tobin, Lad. "Writing relationships: reading students, reading ourselves." (1991).

VanderStaay, Steven L., Beverly A. Faxon, Jack E. Meischen, Karlene T. Kolesnikov, and Andrew D. Ruppel. "Close to the heart: Teacher authority in a classroom community." College Composition and Communication 61.2 (2009): W262.

Wender, Emily. "The practice of empathy." English Journal (2014): 33-37.

Williams, Bronwyn T. "Heroes, rebels, and victims: Student identities in literacy narratives." Journal of Adolescent \& Adult Literacy 47.4 (2003): 342-345.

Williams, Bronwyn T. "Home and away: The tensions of community, literacy, and identity." Journal of Adolescent \& Adult Literacy 49.4 (2005): 342-347.

Williams, Bronwyn T. "Metamorphosis hurts: Resistant students and myths of transformation." Journal of Adolescent \& Adult Literacy 50.2 (2006): 148-153.

Williams, Bronwyn T. "Pay attention to the man behind the curtain: The importance of identity in academic writing." Journal of Adolescent \& Adult Literacy 49.8 (2006): 710-715. 
Williams, James D., and Scott D. Alden. "Motivation in the composition class." Research in the Teaching of English (1983): 101-112.

Woodrow, Lindy. "College English writing affect: Self-efficacy and anxiety." System 39.4 (2011): 510-522.

Young, Morris. "Narratives of identity: Theorizing the writer and the nation." Journal of Basic Writing (1996): 50-75. 